\title{
DISTINCIONES ACERCA DEL CONCEPTO HEGELIANO DE SOCIEDAD CIVIL*
}

\begin{abstract}
C na de las figuras a las que se recurre constantemente en la historia y en el lenguaje de la filosofía política es la pareja sociedad civil-Estado político. Mientras el significado del término «Estado», a pesar de los distintos modos de definirlo, parece mantenerse invariable, el de «sociedad civil» está sometido a una serie de cambios que es preciso indagar. La filosofía del derecho de Hegel -como veremos en la presente aportación- representa el mejor lugar para comprenderlos.
\end{abstract}

\section{Una comparación entre modelos}

En su significado más antiguo y originario, la sociedad civil no presenta grado alguno de autonomía respecto al Estado: sociedad y Estado se entienden dentro de la misma dinámica conceptual ${ }^{1}$. Al comienzo de la Política de Aristóteles es visible el nexo que los une. El Estado, o sea, la sociedad civil hê pólis kái hê koinônia hê politikê, civitas societas civilis sive res publica: ésta es la fórmula clásica que ha constituido la base para la sucesiva reconstrucción ${ }^{2}$. Bajo

${ }^{1}$ Véase al respecto M. Riedel, «Hegels Begriff der 'bürgerliche Gesellschaft' und das Problemseines geschichtlichen Ursprungs», publicado por primera vezen Archiv, Zwischen Tradition und Revolution. Studien zu Hegels Rechtsphilosophie, Erw. Neauausg., Stuttgart, Klett-Cotta, 1982, 2. ${ }^{a}$ ed., pp. 139-169. [Hay tr. cast.: «El concepto de la 'sociedad civil' en Hegel y el problema de su origen histórico», en AA. VV., Estudios sobre la «Filosofía del derecho» de Hegel, Madrid, Centro de Estudios Constitucionales, 1989, págs. 195-222]. Cfr. también M. Riedel, Bürgerliche Gesellschaft und Staat bei Hegel, Neuwied u. Berlin, Luchterhand, 1970, págs. 39-53.

${ }^{2}$ Aristóteles, Política, I (A), 1252a 1-7 [Tr. cast. de C. García Gual y Aurelio Pérez, Política, Madrid, Alianza Editorial, 1986, pág. 41]. La fuerza de la tradición está todavía muy presente en la primera traducción alemana del texto aristotélico, 
este perfil, la tradición clásica permanece aún presente formalmente en el derecho natural moderno.

Hobbes y Locke usan indistintamente uno y otro término; en Christian Wolff, sociedad civil es sinónimo de Estado; incluso Kant, que junto a Fichte es el autor más próximo a Hegel, define el Estado como civitas, según la antigua acepción ${ }^{3}$.

Esta recepción de la tradición es un hecho que hay que tener en cuenta. Sin embargo, no debe absolutizarse, ya que de otro modo se corre el riesgo de colocar en un mismo plano la antigua y la moderna societas civilis. Se omite así la diferencia entre ambas con el fin de mostrar la acción de ruptura llevada a cabo por Hegel en la tradición de la metafísica política desde Aristóteles hasta Kant.

De lo que se trata, en cambio, es de ver cómo al tomar los conceptos del mundo antiguo, se torna consciente de forma gradual la separación frente al mismo. El cambio de acento dentro del propio sistema conceptual es el indicio de una transformación que hay que descifrar. La equivalencia aristotélica se decanta resueltamente en favor de una pólis, que absorbe en su interior cualquier reivindicación de subjetividad. Ahora bien, es el surgimiento de esta subjetividad lo que caracteriza epocalmente al derecho natural moderno. Aquí todo está a favor de la parte opuesta, de lo «civil», e incluso parece sacrificarse el antiguo significado de la pólis. Todo ello sucede sin una transformación lingüística general. Las separaciones son lentas, las variaciones casi imperceptibles. Así, también esta sociedad civil deberá vestiarse de nuevo con la forma-Estado. Parece inmutable aquello que cambia y únicamente

a cargo de J. G. Schlosser, el cual, en efecto, traduce de este modo el punto central del pasaje citado: «nämlich der Staat, oder die bürgerliche Gesellschaft» (Aristóteles, Politik und Fragment der Ökonomie, Aus dem Griechischen übersetzt und mit Anmerkungen und einer Analyse des Textes versehen von J. G. Schlosser, Erste Abteilung, Lübeck, Niemann, 1978, pág. 1).

${ }^{3}$ Desde la perspectiva de la presente investigación bastarán algunas remisiones significativas. Hobbes, en el cap. V del De cive dedicado al problema del origen del poder estatal, afirma: «La unión así creada se llama Estado (civitas), o sea, sociedad civil (...)» [tr. cast. de André Catrysse: De Cive, en la antología preparada por Enrique Lynch con el título Hobbes, Barcelona, Península, 1987, pág. 232]. Locke titula el importante cap. VII del segundo de los Two Treatises of Government: Of Political or Civil Society [tr. cast. de Carlos Mellizo: Segundo Tratado sobre el Gobierno Civil, Madrid, Alianza Editorial, 1990, pág. 96]. Wolff escribe: «Ea philosophiae pars in qua homo consideratur tamquam vivens in Rep. seu statu civil» (Cfr. C. Wolff, Philosophia rationalis sive logica, Verona, Ex Typografia Dionysii Ramanzini, 1735, Discursus praeliminaris de philosophia in genere, cap. III § 65). De Kant véase especialmente los $\S \S 45-46$ de la primera parte de la Metaphysik der Sitten [tr. cast. de Adela Cortina y Jesús Conil: La Metafísica de las Costumbres, Madrid, Tecnos, 1989, págs. 142-145]. 
con Hegel nos damos cuenta que la transformación ha tenido lugar de forma radical.

No obstante, la transformación es ya visible, observando el ritmo dialéctico que da origen a la forma-Estado. Mientras en el modelo aristotélico la pólis es el resultado de un movimiento lineal que presupone al hombre naturaliter social, en el modelo que se remonta a Hobbes la civitas es el punto de llegada artificial, el resultado de un aut-aut. El uso de esta terminología ${ }^{4}$ requiere alguna precisión: a costa del recurso reiterado a un número cada vez mayor de distinciones en el ámbito del mismo fenómeno, es tal vez posible, a un cierto nivel de abstracción, reconducir a un esquema conceptual unitario distintos pensadores como Hobbes, Spinoza, Locke y Kant. En cuanto al problema crucial de la naturaleza del Estado, es posible identificar, empezando por Hobbes y con todas las cautelas debidas al alto grado de abstracción, un modelo que persiste, aunque sea con notables variaciones, hasta Hegel incluyéndole y excluyéndole a la vez ${ }^{5}$. En efecto, de Hobbes a Kant se adopta un modelo (tan formal que permite llenarse con los más diversos contenidos) caracterizado por un mismo método (racional, matematizante) y que responde a un mismo problema (el del fundamento del poder).

No se entiende el carácter del derecho natural moderno si no se compara con la historia de la jurisprudencia europea anterior a aquel cambio. Para los iusnaturalistas, la tarea del jurista no era ya la interpretatio de reglas dadas, cuyo material era siempre el Corpus iuris, sino aquella más amplia que consistía en descubrir las «reglas» de las acciones humanas con la misma certeza con la que se conocen las de «las magnitudes en geometría». Así, pues, la diferencia fue, ante todo una diferencia de método que adquirió inmediatamente valor sistemático.

En el libro I de la Política, Aristóteles explica el origen de la pólis valiéndose de una conocida reconstrucción histórica:

La familia es la comunidad, constituida por naturaleza, para satisfacción de lo cotidiano (...), mientras la primera

${ }^{4}$ Se toma aquí con el significado que le da N. Bobbio, «Il modello giusnaturalistico», Rivista internazionale di filosofia del diritto, IV Serie, L., 1973, págs. 603-622. [Hay tr. cast. de Manuel Escrivá en N. Bobbio, Thomas Hobbes, Barcelona, Paradigma, 1991, págs. 17-47]. Cfr. también la primera parte de N. Bobbio-M. Bovero, Società e Stato nella filosofia politica moderna, Milano, Il Saggiatore, 1979, págs. 17-109. [Hay tr. cast. de Juan Carlos Bayón en N. Bobbio, Estudios de historia de la filosofía: De Hobbes a Gramsci, Madrid, Debate, págs. 73-149].

${ }^{5}$ Ibídem, pág. 37.

${ }^{6}$ El sentido del nuevo método se expresa de una forma especialmente incisiva en la dedicatoria del De Cive. [Tr. cast. cit., págs. 185-361 (185-188)]. 
comunidad, que deriva de la unión de más familias desarrollada para satisfacer una necesidad no cotidiana, es la aldea (...). La comunidad de aldeas constituye la pólis (...). Por lo tanto, está claro que la pólis es un producto natural y que el hombre es, por naturaleza, un ser político (zôon politikon) ${ }^{7}$.

A pesar de que hablar de un modelo aristotélico comporta los mismos problemas y dificultades que hacerlo de un modelo hobbesiano, puede ser significativo constatar su persistencia en el tiempo: aquel mantiene su vitalidad hasta el umbral de la edad moderna ${ }^{8}$. Sólo con la dicotomía estado de naturaleza-estado civil se alcanza una radical transformación. El estado civil ya no es la espontánea prolongación del estado natural, sino el resultado de un contrato (con modalidades de actuación y contenido que varían en cada autor), estipulado por individuos originariamente independientes, que deciden abandonar el estado de naturaleza y dar vida al estado civil dotado de autoridad y legitimado. El modelo se construye en base a estos dos elementos fundamentales. Entre los dos estados no existe continuidad, sino conflicto: el estado civil surge como antítesis del estado natural.

Este modo de proceder se remonta a Hobbes y especialmente a su firme toma de posición contra la concepción aristotélica al comienzo del De cive:

La mayoría de los que escribieron sobre política suponen, afirman o postulan que el hombre es un animal nacido con disposiciones naturales para vivir en sociedad. El hombre es un animal político, zôon politikon, dicen los griegos. Sobre esta base construyen su teoría política, como si para mantener la paz y gobernar todo el género humano sólo hiciera falta que los hombres se pusieran de acuerdo sobre ciertos pactos y condiciones, a los cuales dan entonces el nombre de leyes. Este axioma no deja de ser falso $(. . .)^{9}$.

A poco que se observe, la diferencia entre las dos concepciones no hay que buscarla en el punto de llegada, que siempre es el Estado, sino más bien: a) en el punto de partida, que en el modelo aristotélico

${ }^{7}$ Aristóteles, Política, I (A), 2, 1252b 13-28 y 1253a 1-3 [tr. cast. cit., pág. 43].

${ }^{8}$ Aún en De la république Bodin define el Estado como «el recto gobierno de varias familias con poder soberano» [tr. cast. de Pedro Bravo Gala: Los seis libros de la República, Madrid, Tecnos, 1985, pág. 9].

${ }^{9}$ Cfr. Hobbes, De Cive [tr. cast. cit., págs. 197-198]. 
es la sociedad, mientras en el hobbesiano es el individuo particular del estado de naturaleza ${ }^{10}$; b) en el movimiento que da origen al Estado, que en el primer caso, es lineal y comporta una transformación prevalentemente cuantitativa, $\mathrm{y}$, en el segundo, es discontinuo y comporta un salto de calidad. Dos puntos de partida antitéticos convergen en el mismo resultado. En el pensamiento occidental, es una tendencia constante y un elemento invariable, más allá de las diferencias, considerar al Estado como el momento supremo y definitivo de la vida social del hombre. Esta conclusión, sin embargo, se obtiene partiendo de fuerzas opuestas. Para Aristóteles, los individuos se hallan desde siempre inscritos en un orden social que los conforma. Hobbes, en cambio, arranca de individuos aislados, a partir de los cuales, mediante contrato, surge el Estado. En aquél, el inicio era la sociedad; en éste, el individuo. En el primer caso, el estado civil deriva de un movimiento abierto, gradual, que partiendo de la familia llega a la pólis. En el segundo, el estado civil únicamente puede ser consecuencia del abandono del estado de naturaleza, por consiguiente, de la unión de individuos originariamente dispersos.

Desde el punto de vista ideológico está claro que este segundo caso podía contemplarse como el reflejo teórico $\mathrm{y}$, a la vez, el proyecto político de la incipiente sociedad burguesa. Y, en efecto, de este modo lo interpretó Marx:

El pescador y el cazador individual y aislado, con el que comienzan Smith y Ricardo, pertenece a las imaginaciones carentes de fantasía de las Robinsonadas del siglo XVIII, que en modo alguno expresan, como se imaginan los historiadores de la civilización, simplemente una reacción frente al superrefinamiento y un retorno a una vida natural mal comprendida. De la misma forma que tampoco descansa sobre tal naturalismo el contrato social de Rousseau, que pone en conexión y relación mediante el contrato a sujetos independientes por naturaleza. Esta es la apariencia (...). En realidad, se trata más bien de la anticipación de la «sociedad burguesa» (...). Cuanto más nos remontamos en la historia, tanto más se nos presenta el individuo productor, como dependiente, como perteneciente

${ }^{10}$ Aunque también es cierto que, en el ámbito del propio modelo desde Hobbes-Spinoza hasta Locke-Kant, el concepto de status naturalis tiende a transformarse en una societas naturalis, es decir, en una auténtica sociedad prepolítica que comprende todas las relaciones económicas y sociales que los individuos mantienen entre sí. Pero eso (que constituye la variación más notable en el modelo) no contradice el arranque individualista de las teorías iusnaturalistas. El punto de partida no es el appetitus societatis, sino el conatus sese conservandi de Spinoza. 
a un todo mayor: primero de forma todavía completamente natural en la familia y en la familia ampliada que se convierte en tribu; más tarde en la comunidad en sus diferentes formas que procede de la contraposición y fusión de las tribus (...). El ser humano es, en el sentido más literal del término, un zôon politikon, no sólo un animal social, sino además un animal que sólo se puede aislar en sociedad ${ }^{11}$.

El Rousseau del que habla Marx es asimilado por completo (siguiendo la interpretación hegeliana) a la doctrina del derecho natural moderno. La lectura de un Rousseau teórico del individualismo ha condicionado fuertemente el juicio de Marx. Poco importa en esta sede establecer si Marx ha malinterpretado o no a Rousseau. El hecho aquí decisivo es que lo critique recurriendo a Aristóteles. Marx toma casi literalmente el pasaje de la Política anteriormente citado; critica a Rousseau por medio de Aristóteles, la societas civilis del iusnaturalismo moderno mediante el zôon politikon de la política clásica. A decir verdad, se trata de una operación no especialmente original, ya que había sido realizada antes que Marx por Hegel. Pero con Marx nos encontramos al final de un proceso: la sociedad burguesa de la que habla no es ya la sociedad civil de los iusnaturalistas y tampoco la de Hegel. El propio término cambia hasta tal punto su significado que Marx en la Judenfrage ${ }^{12}$ identifica el espíritu de esta sociedad con el bellum omnium contra omnes, cuando, en cambio, en el modelo hobbesiano, la sociedad se constituía precisamente con el fin de superar el estado de guerra originario. De todos modos, el origen de tal transformación hay que buscarlo en el concepto hegeliano de una sociedad cuyo centro se traslada de la política a la economía.

\section{Aspectos y figuras de la sociedad civil}

2. 1. Es preciso esperar hasta el primer curso de lecciones de Hegel sobre la filosofía del derecho para encontrar un tratamiento de

${ }^{11}$ K. Marx, Grundrisse der Kritik der politischen Ökonomie (1857-58) [tr. cast. de Javier Pérez Royo: Líneas fundamentales de la crítica de la economía política, en OME-21 (Obras de Marx y Engels), Barcelona, Grijalbo, 1977, págs. 6-7. En esta versión castellana se habla de «sociedad civil», donde la italiana utiliza la expresión «sociedad burguesa»; la elección de esta última para el presente texto, pues, obedece tan sólo a razones de fidelidad respecto a los términos empleados por Becchi (N. del T.)].

${ }^{12}$ K. Marx, Zur Judenfrage (1843) «(...) el espíritu de la sociedad civil, del ámbito del egoísmo, del bellum omnium contra omnes» [tr. cast. de José María Ripalda: «La cuestión judía» en Manuscritos de París. Escritos de los «Anuarios Francoalemanes», OME-5, Barcelona, Grijalbo, 1978, págs. 178-208 (188)]. 
la sociedad civil independiente del Estado. En la Enciclopedia de Heidelberg falta todavía una consideración autónoma de este momento. A partir de aquel primer curso (en el que se encuentra ya toda la articulación presente en el texto publicado), la historia de la sociedad crece de forma desmesurada.

En el concepto de sociedad civil, Hegel comprende, ante todo, la necesidad histórica y la formación de una sociedad despolitizada centrada en la economía. El avance de la economía mediante la división del trabajo y la introducción de las máquinas en el sistema productivo comporta una verdadera revolución en las relaciones entre los hombres, que Hegel pone agudamente de relieve, señalando sus aspectos negativos y dramáticos. La economía, que originariamente no era otra cosa que el conjunto de reglas para el gobierno de las familias y estaba totalmente subordinada a la política, adquiere no sólo una dimensión autónoma, sino una verdadera preponderancia. Se modifica primeramente el contexto en el que se introduce. En la antigüedad, la economía no se había separado de la familia. Sólo cuando el valor de cambio se separa progresivamente de la esfera doméstica, del oikos, tiene lugar una apretada red de intercambios sociales que se extienden más allá del núcleo familiar originario.

Al final, el hombre, según la conocida imagen de Hegel, pasa a ser «hijo» (Rph § 238) de la sociedad civil, y la economía tiende a adquirir el valor que en otras épocas tuvieron la religión o la política.

El «sistema de las necesidades» de Hegel constituye la introducción filosófica al problema de la political economy clásica. En esta ciencia, Hegel reconoce la ideología de una realidad histórica emergente: la sociedad burguesa. El contenido esencial de la misma son las necesidades del hombre y su satisfacción a través del trabajo. Con anterioridad a Hegel, sólo Locke había introducido el concepto de trabajo como factor determinante en el ámbito de la moderna filosofía jurídica y política ${ }^{13}$. Es la intersección necesidad-trabajo, multiplicidad de necesidades-multiplicidad de medios para satisfacerlas,

${ }^{13}$ Cfr. el cap. V del segundo de los Dos Tratados sobre el gobierno [tr. cast. cit., págs. 55-75]. Sobre esta circunstancia, normalmente omitida, ha llamado la atención N. Bobbio en el artículo «Hegel y el iusnaturalismo» (1966), ahora en Studi hegeliani, Turín, Einaudi, 1981, págs. 3-33. [Hay tr. cast. de Alejandro Rossi: «Hegel y el iusnaturalismo», en AA.VV., Estudios sobre la «Filosofía del Derecho» de Hegel, Madrid, Centro de Estudios Constitucionales, 1989, págs. 377-406]. Véase también F. M. De Sanctis, «Lavoro, propietà, industria. Il capitolo V del 'Secondo Trattato' di Locke, Materiali per una storia della cultura giuridica, XVIII (1988), 2, págs. 311-328 (ahora en F. M. De Sanctis, Dall'assolutismo alla democrazia, Saggi, Turín, G. Giappichelli, págs. 79-104). Alusiones a una posible influencia de Locke sobre Hegel se encuentran en el escrito de P. Chamley, «Les origines de la pensée economique de Hegel», Hegel Studien, 3, 1965, págs. 225-261. 
lo que produce un progresivo desarrollo en la división del trabajo y exige la introducción de máquinas en el modo de producción.

La dialéctica generada a partir de las complicaciones y de la expansión de este sistema se mueve entre la «acumulación de riquezas» y la «singularización y limitación del trabajo particular, y con ello la dependencia y miseria de la clase ligada a ese trabajo» (Rph $\S 243$, pág. 682. 12-14).

Por ejemplo, en la obra publicada, Hegel parece pensar todavía que las exportaciones $(R p h \S 246)^{15}$ y la colonización $(R p h \S 248)^{16}$ son remedios eficaces para combatir la crisis de sobreproducción. En las lecciones, tales ilusiones parecen desvanecerse. Es significativo que Hegel, viviendo la crisis de 1825 (aquella crisis con la que -según Marx- la gran industria inauguraba «el ciclo periódico de su vida moderna»), se percate cada vez más de lo vanos que resultan los remedios propuestos.

Las lecciones correspondientes al curso 1824/25 (Rph VI) documentan claramente este cambio de perspectiva ${ }^{17}$. Este curso es, de entre todos, aquel en que Hegel demuestra tener una conciencia más lúcida de los mecanismos de desarrollo de la sociedad capitalista y de sus estridentes contradicciones. Si en el texto publicado, Hegel se limita en el fondo a tomar en consideración los intentos de solución

\footnotetext{
${ }^{14}$ Acerca del significado de estas lecciones en general, cfr. ahora P. Becchi, «Las nuevas fuentes para el estudio de la Filosofía del derecho hegeliana», Doxa, 8 (1990), págs. 221-239.

${ }^{15}$ Cfr. Rph $§ 246$ : «Por medio de esta dialéctica suya la sociedad civil es llevada más allá de sí; en primer lugar más allá de esta determinada sociedad, para buscar en el exterior consumidores y por lo tanto los necesarios medios de subsistencia en otros pueblos que están atrasados respecto de los medios que ella tiene en exceso o respecto de la industria en general».

${ }^{16}$ Cfr. Rph $\S 248$ : «Esta ampliación de las relaciones ofrece también el recurso de la colonización, a la cual -en forma esporádica o sistemática- tiende la sociedad civil avanzada. Por su intermedio la sociedad proporciona a una parte de su población un retorno al principio familiar en otra tierra, y se da a sí misma una nueva demanda y un nuevo campo para su trabajo».

${ }^{17}$ Losurdo, pues, tiene razón cuando escribe que «el análisis más profundo del carácter implacable de la crisis de sobreproducción se encuentra en las lecciones de 1824-25» (pág. 120); y poco después observa que, si bien todavía subsisten en el texto publicado algunas ilusiones, «en las lecciones siguientes (...) se filtra un creciente escepticismo acerca de los remedios de las exportaciones y de las colonizaciones» (pág. 128). (Las citas son tomadas de D. Losurdo, Tra Hegel e Bismarck. La rivoluzione del 1848 e la crisi della cultura tedesca, Roma, Ed. Riuniti, 1983). Si eso es cierto, entonces deberá admitirse también que existen diferencias relevantes entre el texto publicado y las lecciones. Por tanto, no comprendo muy bien el sentido de su trabajo más reciente (Hegel, Marx e la tradizione liberale, Roma, Ed. Riunti, 1988), en el que se insiste, en cambio, en la necesidad de una lectura unitaria.
} 
que entonces se discutían, en las lecciones esos intentos se contemplan con creciente escepticismo.

Cuando la «producción excede la necesidad de consumo», la sociedad civil se ve «impelida a fundar colonias» (Rph VI $\S 248$, págs. 614. 18-22) para resolver el problema de la gran masa que no puede ya satisfacer las propias necesidades con el trabajo. Pero ahora este remedio se contempla teniendo en cuenta su inestabilidad; sólo momentáneamente puede desviar las contradicciones. Cuando la colonización tiene lugar de forma «esporádica», es decir, cuando se confía a la iniciativa particular, es totalmente insatisfactoria: «los colonos (...) quedan desvinculados de sus respectivas madre patrias, a las cuales no aportan ventaja alguna; se abandonan a la accidentalidad de ganarse el pan» (Rph VI $§ 248$ A pág. 614. 25-28). El problema de la miseria, pues, no se resuelve, sino que simplemente se aplaza. Distinto es el caso en que la colonización es «sistemática», o sea, cuando a la cual quedan estrechamente unidas. En este último caso, el problema de la miseria parecería resuelto, al menos de modo provisional. Sin embargo, tampoco en esta ocasión puede ocultarse que «los ciudadanos de las colonias (...) tienen menos derechos que los ciudadanos de la madre patria» (Rph VI $\S 248$ A pág. 615. 27-28). Prescindiendo de estas discriminaciones, las mismas contradicciones presentes en las metrópolis están destinadas a reproducirse en poco tiempo también en las colonias.

Hegel se muestra aún más escéptico por lo que a las exportaciones se refiere. En $1824 / 25$, Hegel, a quien no se le escapa la conexión entre desarrollo del comercio exterior y colonización, está tan poco persuadido de la eficacia del recurso a las exportaciones como para darse cuenta del hecho de que éstas, si bien atenúan en el país exportador las consecuencias de la crisis de sobreproducción, acaban produciendo en el país importador consecuencias todavía más graves. Merece recordarse un ejemplo:

Los ingleses importan algodón en rama de la India, pero la fabricación de artículos de algodón ha aumentado tanto que exportan de nuevo estos artículos de la India, obstaculizando de este modo la fabricación en este país, fabricación que da empleo a varios millones de hombres (Rph VI § 236 A pág. 601. 3-7).

Son consideraciones que no valen únicamente en lo tocante a la relación con las colonias; en la misma página Hegel dice que «en el continente muchas fábricas se ven aniquiladas a causa de las máquinas inglesas» (Ibíd. 1-3). ¡Y hablaba probablemente pensando que muchas de aquellas fábricas eran alemanas! Por otro lado, si al 
exportar sus mercancías Inglaterra conseguía exportar también la crisis, no por ello lograba vencer sus consecuencias internas. Hegel lo pone claramente de relieve cuando afirma:

No existe otro país en el que se produzca tanto, ni que tenga un mercado mayor; con todo, la miseria y la plebe en ninguna otra parte están presentes en tan alta medida y de forma tan terrible como en Inglaterra (Rph VI $§ 245$ A pág. 611. 5-8). El mismo escepticismo que Hegel demuestra tener respecto a los remedios indicados, lo manifiesta también en relación al proyecto de emplear la mano de obra excedente en workhouses especiales. Una propuesta así, de impronta malthusiana, debería haber permitido resolver en Inglaterra el dramático problema del desempleo y de la consiguiente pobreza. Ante tal propuesta, Hegel tampoco esconde su perplejidad. Ya en el curso anterior de 1822/23 observaba: «si, por ejemplo, las instituciones para los pobres, tal como existen allí [en Inglaterra], ofrecen sus productos a buen precio, entonces se quita el pan a los demás que hasta ahora se lo ganaban» (Rph V § 245 A pág. 704. 6-10). Tampoco cree Hegel que puede acudirse a una especie de trabajo a domicilio:

Se da trabajo a los pobres, se les abastece de material y se compra sus productos. Parece ser el modo más adecuado, el más justo, pero considerado con más atención este proceder no elimina la pobreza, tiene, si cabe, un efecto aún peor (Rph VI $\S 245$ A. p. 611.28-31).

Lejos de contribuir a la solución del problema de la pobreza, tales remedios conducían sin más a la sobreexplotación de algunos sectores de trabajadores. Ni siquiera una rigurosa política de intervención del Estado en la economía parecía en condiciones de resolver el problema. En efecto, Hegel no desconoce el hecho nuevo de que el dinero (como potencia abstracta e independiente) y la acumulación de riqueza en circulación pueden incluso limitar y condicionar la propia soberanía del Estado. El movimiento de capital que parece extenderse desmesuradamente se manifiesta de forma rotunda en las lecciones de 1824/25. En ellas, Hegel llega a decir que los bancos dictan las leyes a los gobiernos y a la política:

Puesto que el dinero es el gran medio, la clase comercial está ahora muy ligada a la política. Se encuentra tan implicada en las necesidades de los distintos Estados y en el comercio 
del dinero, que los bancos han adquirido enorme importancia (...); dado que los Estados tienen necesidad de dinero para perseguir sus intereses, dependen de esta circulación de dinero en sí mismo independiente (Rph VI $\S$ A págs. 520. 27-32 y 521. 1-2).

El análisis de estas lecciones podría continuar, pero los elementos sobre los que he incidido me parecen suficientes para llegar a la conclusión de que, en ellas, Hegel, antes aún de avanzar respuestas, plantea sus dudas y su perplejidad en torno a las que se ofrecían en aquella época. El «sistema de las necesidades», abandonado a su propia dinámica, sólo conduce a la trágica realidad de que la riqueza y la pobreza aumenten conjuntamente:

En Londres, ciudad infinitamente rica, la necesidad, la miseria, la pobreza son tan terriblemente grandes que cuesta hacerse una idea. Al aumentar la riqueza, ésta se concentra en pocas manos y la diferencia pasa a ser cada vez mayor, ya que el hecho de la concentración de grandes capitales permite adquirir a precios más ventajosos que en el caso de poseer un patrimonio exiguo (...). Los ricos se toman desconsiderados, quieren ganar aún más, se arriesgan; la envidia, que se basa en el impulso a la igualdad, termina por arruinar a muchos hombres. En pocas palabras, existen una infinidad de combinaciones posibles que dan pie a la pobreza y otras tantas que producen riqueza. Si por un lado se encuentra la riqueza, por el otro debe hallarse la pobreza ( $R p h$ VI $§ 195$ A págs. 492. 22-28 y 495. 1-7).

En relación al carácter inevitable de esta dialéctica, por la cual al aumento de la riqueza corresponde necesariamente al aumento de la pobreza, Hegel no ofrece ninguna solución. Cuando habla de la pobreza y del medio de corregirla, admite que «a esta pregunta es muy difícil responder», puesto que «la desproporción de la riqueza hace que la sociedad civil se empobrezca hasta el punto de no poder remediar la desproporción de la plebe» (Rph VI § A pág. 611. 13-16).

2.2. Lo que hasta ahora he puesto de relieve, basándome principalmente en fragmentos de las lecciones de 1824/25, permite comprobar con cuanta atención siguió Hegel el desarrollo de la sociedad burguesa y de sus contradicciones. Sin embargo, la imagen de la sociedad que se desprende de aquella descripción no es todavía la de la sociedad civil hegeliana. En Hegel tienen lugar un doble movimiento 
ya perceptible desde sus primeras lecciones. La economía se extiende de la societas domestica a la societas civilis; esta última, cargada de nuevo contenido, no se identifica ya con el Estado en la totalidad de sus atribuciones. Dos pasos adelante y uno atrás. El resultado es una sociedad que contiene en su interior el sistema de las necesidades y, sin embargo, no se identifica simplemente con él. La complejidad de la sociedad civil hegeliana se resiste a quedar reducida a la recepción filosófica de los contenidos de la economía política. Este nudo no se dejar cortar con la espada de Smith y Ricardo. Bajo la guía del «sistema de las necesidades» se ha ido consolidando una interpretación (cuyos orígenes hay que buscar en Marx), que tiende a identificar la descripción hegeliana de la sociedad civil con la sociedad moderna basada en el trabajo industrial. Desde este prisma se han ido multiplicando, sobre todo por el marxismo, los estudios acerca de la relación de Hegel con la economía política, destinados a mostrar, por un lado, la profundidad de la comprensión hegeliana del intercambio y del trabajo abstracto, y, por el otro, la homogeneidad entre el estatuto «lógico» de la filosofía y la teoría de las «necesidades» de la economía política ${ }^{18}$.

No es menos cierto que también por parte de algunos autores de inspiración marxista se ha descubierto la «categoría de lo político», disminuyendo el predominio tan extenso de la economía ${ }^{19}$. No obstante, no creo que la supremacía del interés por las categorías económicas haya decaído; tanto es así que resurge en algunos estudios recientes ${ }^{20}$. De este modo, la parte continúa confundiéndose con el todo, y el «sistema de las necesidades», que no es más que el momento inicial de la sociedad civil, se superpone a la totalidad de

${ }^{18}$ Limitándonos a la literatura italiana, recuérdese: M. Cacciari, «Pensiero negativo e razionalizzazione. Problemi e funzione della critica al sistema dialettico» (1973), ahora en Pensiero negativo e razionalizzazione, Venecia, Marsilio, 1977, págs. 13-69; F. Consiglio, «Bisogno e valore nella 'Filosofia del diritto' di Hegel, Giornale Critico della filosofia italiana, LIV 9LVI (1975), págs. 522-548; R. Bodei, R. Racinaro, M. Barale, Hegel e l'economia politica, a cargo de S. Veca, Milán, Mazzotta, 1975. D. Borso, Hegel politico dell'esperienza, Milán, Feltrinelli, 1976; F. Fistetti, Critica dell'economia e critica della politica. Marx, Hegel e l'economia classica, Bari, De Donato, 1976.

${ }^{19}$ Desde este punto de vista me parece significativa la lectura de M. Tronti, Hegel politico, Roma, Instituto della Enciclopedia italiana, 1975 y el ensayo de M. Cacciari, Dialettica e critica del Politico. Saggio su Hegel, Milán, Feltrinelli, 1978. Ambos ensayos fijan su atención -aunque desde ángulos distintos- en la desviación que caracteriza el discurso de Hegel respecto a la economía política.

${ }^{20}$ Objeción que puede hacerse a D. Losurdo, Tra Hegel e Bismarck. La rivoluzione del 1848 e la crisi della cultura tedesca, cit., págs. 111-239. Véase al respecto P. Becchi, «Hegel la coscienza della crisi e il fascino del politico», Materiali per una storia della cultura giuridica, XXV (1985), págs. 261-274. 
sus momentos. Contra esta vieja y nueva tendencia es preciso afirmar que la sociedad civil, tal como la entiende Hegel, no es únicamente la descripción del sistema de la economía y de las relaciones a ella inherentes. En la primera parte, el conjunto de estos momentos se trata al nivel más bajo. En la segunda y la tercera parte, en cambio, se discuten temas de naturaleza esencialmente jurídica y político-administrativa. En esta articulación sistemática, las filosofías del derecho de Hegel concuerdan entre sí.

Tal vez haya que repetir una vez más que la distinción entre sociedad civil y Estado, entendida como distinción entre economía y política, es obra de Marx y no de Hegel. El sistema hegeliano es más complejo ${ }^{21}$.

La economía no coincide con la sociedad, la cual comprende también momentos de regulación jurídica y de organización sociopolítica, del mismo modo que la política no coincide simplemente con el Estado. El modelo dicotómico economía-política puede sustituirse por uno tricotómico economía-sociedad-Estado, en el que la sociedad ocuparía todo el campo intermedio, sede de conflictos tanto económicos como políticos. Es una sucesión algo forzada, pero no creo que contradiga el planteamiento general de la construcción hegeliana.

Hay de hecho en el interior de la sociedad civil un complejo ordenamiento jurídico y político (no confundirlo con el ordenamiento propiamente estatal), que responde a las necesidades de la sociedad. Precisamente por este motivo no es exacto creer que para Hegel la política encuentre su único lugar de realización en el Estado. También esta tesis, de gran predicamento entre los estudiosos italianos ${ }^{22}$, presenta algún problema. Bajo la estela de esta posición se ha

${ }^{21}$ Sobre este punto merecer recordarse lo que escribía N. Bobbio en la reseña «La filosofia giuridica di Hegel nell’ultimo decennio» (1972), ahora en Studi hegeliani, cit., págs. 159-192: «Bajo la guía de Marx (...) el análisis del sistema de las necesidades, que sólo constituye su primera parte, para dar pie a la falsa representación de la sociedad civil como espacio de las relaciones económicas (...) Quede dicho de una vez para siempre que la identificación entre sociedad civil y espacio de las relaciones económicas, o, lo que es lo mismo, la distinción entre sociedad civil y Estado como distinción entre sociedad económica y sociedad política, es obra de Marx y no de Hegel: referirla, como sucede frecuentemente, a Hegel es simple y llanamente una deformación de su pensamiento» (163).

${ }^{22}$ En este sentido se había ya manifestado G. Solari, «Il concetto di società civile in Hegel», Rivista di filosofia, XXII, 1931, págs. 299-347, publicado más tarde en Studi storici di filosofia del diritto, Turín, Giappichelli, 1949, págs. 343-381 y ahora en La filosofia política, a cargo de L. Firpo, Roma-Bari, Laterza, 1974, págs. 209-265: «En la doctrina de la sociedad de Hegel está implícita una teoría del Estado (...). Es el Estado quien mantiene y defiende el orden jurídico y la eticidad que le corresponde en una comunidad, cuyos miembros se proponen finalidades económicas 
llegado a afirmar que la sociedad civil es ya una forma de Estado, esto es, la civil society de Locke y el Estado de derecho de Kant y Humboldt. Es verdad que en el texto publicado (también en las lecciones) se deja espacio a esta interpretación. Exactamente en el $\S 183$ (así como en el $\S 157$ y en el $\S 187$ ) Hegel escribe que este sistema (la sociedad civil) puede considerarse como "estado exterior, como estado de la necesidad y del entendimiento» (Rph § 183 pág. 633. 19), lo cual parece legitimar aquella hermenéutica. Pero, en realidad, esta explicación (con asidero en los textos) presenta más problemas de los que de hecho resuelve.

En efecto, se llega así a la paradójica conclusión de que en Hegel estarían presentes al menos dos distintas formas de Estado igualmente legitimadas: una, orientada en sentido claramente liberal (la sociedad civil), la otra, en un sentido no tan claramente definido, pero en todo caso totalitario (el Estado ético). No obstante, creo que nadie hasta ahora ha logrado explicar cómo pueden coexistir dos imágenes tan distintas de Estado, o, mejor aún, cómo el mismo autor, en la misma obra, puede sostener dos concepciones del Estado inconciliables entre sí.

Además, siguiendo esta interpretación, queda básicamente sin resolver el problema de la relación entre la sociedad civil y el Estado político. Y ello es comprensible, ya que, en un cierto sentido, la sociedad civil como tal está ausente: ella es ya Estado. Por otro lado, no es menos cierto que Hegel usa las expresiones indicadas no sólo en el texto publicado, sino también en sus lecciones (a partir de Rph I 899 pág. 108. 24-26). El problema, pues, permanece abierto.

Se podría avanzar una nueva hipótesis, a saber, que en aquel contexto "Staat» no debe entenderse en el sentido de «Estado», sino como «estado», status ${ }^{23}$. Desde este punto de vista, Hegel sólo habría querido decir que, a ese nivel de exposición, el sujeto tiene un status distinto al que tiene en la familia o en el Estado. El sujeto no

(...)» (págs. 243 y ss.). Esta tesis ha sido retomada principalmente por N. Bobbio, «Lo studio di Hegel» (1972), ahora con el título «Sulla nozione di 'società civile'», en Studi hegeliani, cit., págs. 147-158 (152) (de Bobbio, véase también -se trata de un trabajo distinto del anterior- «Sulla nozione di 'società civile'», De Homine, 24-25, 1968, págs. 21 y ss.) y por G. Marini, «Structura e significati della società civile hegeliana», en Il pensiero politico di Hegel. Guida storica e critica, a cargo de C. Cessa, Roma-Bari, Laterza, 1979, págs. 57-82 (65-69). [Hay tr. cast.: «Estructura y significados de la sociedad civil hegeliana», en AA.VV. Estudios sobre la 'Filosofía del derecho' de Hegel, Madrid, Centro de Estudios Constitucionales, 1989, págs. 223-248].

${ }^{23}$ Sustancialmente, es esta la tesis avanzada por Ilting en su Comentario al primer curso de lecciones sobre la filosofía del derecho (cfr. notas 195 y ss., pág. 317 de la edición alemana citada). 
es ya miembro de una comunidad política (el Estado); por el contrario, la comunidad pasa a ser para él algo «externo», y, sin embargo, tal condición es necesaria para la «satisfacción» de sus necesidades. No se me escapa que esta aproximación interpretativa, si bien supera algunos obstáculos, también los crea.

La mayor dificultad surge cuando Hegel trata a nivel de sociedad civil los temas de la administración de justicia y de la policía, dos esferas de competencia del Estado. La sociedad civil parece extraerse de dos principios: por un lado, en ella se manifiestan los intereses privados en su libre juego, mediatizado sólo por la pertenencia de los individuos a los distintos grupos sociales; por el otro, este tiene reglas precisas, que, sin salirse de él, tutelan su desarrollo mediante órganos particulares puestos a su servicio. En otras palabras, la sociedad no ofrece únicamente el espectáculo de la disolución del ethos, sino que representa además una particular imagen de recomposición jurídica y administrativa. Junto a la vida económica se presenta en toda su amplitud una determinada forma de organización jurídica. El juego de intereses inarmónicos no puede abandonarse a su suerte, requiere reglas precisas e instituciones adecuadas que lo hagan respetar. Para que funcione, el sistema de las necesidades necesita aparatos de mediación que, al reducir su inmediatez, garanticen además su desarrollo.

Una sociedad de este tipo es, por tanto, al mismo tiempo «burguesa» y «civil». Sin que con el término «burguesa» se quiera identificar a una particular clase social, sino, de forma más abstracta, el momento de la vida económica tout-court; «civil», por su parte, se usa en el sentido que recibe en la expresión «derecho civil» contrapuesto a «derecho público». Así como entre los juristas se puede hablar de «derecho civil-burgués», del mismo modo, respecto a Hegel, cabe hablar de «sociedad civil-burguesa». Teniendo en cuenta que, en esta expresión, «civil» no tiene nada que ver con el status civilis (por lo tanto, el Estado) del derecho natural moderno.

A pesar de lo anterior, aún queda en el alero el hecho de que Hegel trate elementos de derecho público a nivel de derecho privado. Pero tampoco creo que esto pueda ser un argumento suficiente para sostener que, en última instancia, la sociedad civil es ya, de alguna forma, Estado. La esfera de la administración de justicia y de la administración pública son instrumentos necesarios para el desarrollo de la sociedad. Ambos extremos están tan vinculados entre sí, que sin aquéllos, ésta no podría existir. Pero lo que aquí está en discusión no es la justicia y la policía en cuanto aparatos de una forma-Estado, sino en cuanto medios necesarios para garantizar el sujeto que trabaja en la sociedad la satisfacción de sus necesidades. Así, este sujeto, que en la sociedad burguesa ha perdido cualquier vínculo 
con la universalidad, tiende a adquirirlo de nuevo en el interior de la sociedad a través del derecho y de la administración. Pero una tendencia de esta índole podrá llevarse a cabo únicamente a un nivel superior: el del Estado entendido como comunidad política.

No se trata, pues, de pensar en distintas formas de Estado, sino en una sociedad que engloba en su interior instrumentos que parecen necesarios para su autorregulación. Cierto es que queda en pie el dato fáctico de que Hegel en este lugar hable de Estado. Mas es preciso recordar que en el mismo contexto -con mucha precisión en Rph I (§ 89 A pág. 108. 28)- Hegel añade: «Aquí los ciudadanos son bourgeois y no citoyens». También es verdad que poco después Hegel repite que «los ciudadanos de este Estado son personas privadas» (Rph I § 91 pág. 110. 36), pero, de todos modos, es difícil imaginar un Estado en el que los ciudadanos sean y actúen sólo como personas privadas. En definitiva, las oscilaciones de Hegel en este punto me parecen evidentes. Y cabe preguntarse si esta circunstancia no debe conducir a un replanteamiento general del concepto hegeliano de sociedad civil.

2.3. Después de estas observaciones, que al menos habrán servido para comprender lo problemático del concepto hegeliano de sociedad civil, quisiera ahora detenerme en algunos aspectos de la parte que Hegel dedica a la administración de justicia. Tomaré como indicador la versión del texto publicado, con alguna referencia (cfr. infra, 2.4.) a los cursos de lecciones posteriores. Si bien Hegel nunca ha dado tanta importancia a los problemas ligados a la función del derecho en una sociedad compleja como lo hizo en el primer curso ${ }^{24}$, puede ser aquí oportuno presentar en sus líneas esenciales esta parte tal como aparece en la versión publicada.

La administración de justicia corresponde en Hegel a aquella particular Verfassung (no confundir con la del Estado) llamada a regular y a defender mediante un sistema de leyes la libertad y la propiedad de los individuos: «la constitución jurídica, como medio para la seguridad de las personas y de la propiedad» (Rph § 157 pág. 572. 17-18). Con la administración de justicia la sociedad civil vuelve a su concepto, «a la unidad de la universalidad existente en sí con la particularidad subjetiva, aunque ésta sólo en el caso particular

${ }^{24} \mathrm{Si}$ en las lecciones siguientes a la publicación de la Filosofía del derecho de 1820 es evidente el vivo interés de Hegel por los mecanismos de desarrollo de la sociedad capitalista, en su primer curso de lecciones parece conceder un mayor peso a los problemas vinculados a la administración de justicia. Sobre este extremo no puedo aquí sino remitir en general a mi libro Le filosofie del diritto di Hegel, Milano, F. Angeli, 1990, págs. 107-147. 
y aquélla en el sentido del derecho abstracto» (Rph § 229 pág.675. 2-4).

La particularidad del sujeto y la universalidad del derecho abstracto retornan como temas específicos de la sociedad civil y con ellos se concretan y realizan todos aquellos momentos que Hegel había discutido en la primera parte: la posesión y la propiedad, el contrato, lo ilícito. El elemento «abstracto» del derecho lleva a la sociedad civil y penetra en su centro, en la administración de justicia o, literalmente, del derecho («Rechtspflege»). Aquí la libertad abstracta, cerrada y contenida dentro de sí, deviene libertad formal (civil). ¿Cómo? Mediante un sistema de leyes y códigos:

Lo que el derecho es en sí está puesto en su existencia objetiva (...): es la ley. Por esta determinación el derecho es derecho positivo (Rph § 211 págs. 654-655).

Únicamente con la existencia de la ley, el derecho abstracto deviene positivo y adquiere concreción. Este es el punto de vista que caracteriza el texto de Hegel publicado.

Es característico de la ley el que se exprese como regla de comportamiento válida para todos. Su forma consiste en tener validez y en ser conocida, en cuanto ley escrita, por todos los ciudadanos; su contenido procede del material jurídico de una época histórica pensado en su universalidad determinada.

A través de la existencia de la ley el derecho abstracto se hace concreto y concretamente cognoscible por todos. Hegel es decididamente contrario a pensar la justicia como si se tratase de un monopolio de los juristas. Entre quien quiere un código que todos puedan conocer y quien quiere el derecho como «propiedad» de sus científicos (Rph $\$ 228$ A), Hegel se coloca de parte del primer grupo. Aparece aquí en toda su amplitud la contraposición con la Escuela histórica. En su escrito más famoso, Savigny había sostenido el papel decisivo del gremio de los juristas en la producción del derecho. Para Hegel, en cambio, es la ley la fuente privilegiada, si no exclusiva, del derecho; es ella el «Shiboleth ${ }^{25}$ con el que se distinguen los falsos hermanos y amigos del pueblo» (Rph pág. 66. 11-12). La afirmación se encuentra de nuevo en la parte más violentamente polémica del Prefacio, que Ilting titula Der Irrationalismus

${ }^{25}$ [«Shiboleth» (espiga) es la palabra hebrea cuya pronunciación sirvió al juez Jephté para distinguir a los enemigos efrateos que negaban su origen (Jueces, 12, 5 y 6). Con posterioridad se usó en un sentido más general para denominar cualquier signo distintivo, especialmente entre distintas facciones (N. del T.)]. 
der Friesianer (Rph págs. 63-66), pero tras la airada polémica con Fries se entrevé aquella contra Savigny ${ }^{26}$.

El paso de la crítica de Fries a Savigny es perceptible en una pasaje algo anterior al citado: «la particular forma de mala conciencia que se manifiesta en la elocuencia con que se pavonea esta superficialidad: cuanto menos espiritual es, más habla del espíritu, cuanto más muerto e insípido es su discurso, más se usa las palabras vida y vivificar, cuanto mayor egoísmo y vacía altanería muestra más que nunca tendrá en la boca la palabra pueblo» (Rph pág. 65. 24-31). El pasaje empieza con una inconfundible remisión a Fries, pero prosigue con una cadena de asociaciones que en un contexto análogo harán referencia a Savigny. Al hablar de los «derechos consuetudinarios», en el $\S 211$, Hegel observa: «Es una ilusión pensar que por su forma, es decir por ser consuetudinarios, tienen la ventaja de que se han convertido en vida (por lo demás, hoy se habla con preferencia de la vida y del convertirse en vida precisamente cuando se cae en la materia y los pensamientos más muertos» (Rph $\S 211 \mathrm{~A}$ pág. 655. 25-28, 656. 1-3). De este modo, quien pretende destruir el orden legal existente se asimila, de manera bastante, a quien, con el fin de defender el mismo orden, contrapone a la ley el «derecho de los juristas» ${ }^{27}$.

La crítica de Hegel, pues, presupone toda la polémica sobre la oportunidad política de la codificación. Exactamente en el párrafo citado Hegel continúa:

Negar a una nación culta o a la clase jurídica la capacidad de hacer un código es uno de los mayores insultos que puede sufrir esa nación o esa clase (Rph $§ 211$ A pág. 657. 12-14 y 18-20).

Aun sin nombrarlo, Hegel polemiza aquí claramente con Savigny y se coloca de la parte de Thibaut. Igual que para éste, también para

${ }^{26}$ Esta cuestión es comprendida con lucidez por G. Marini, «La polemica con la Scuola storica nella 'Filosofia del diritto' hegeliana», Rivista di filosofia, LXVIII (1977), págs. 169-204 (177), ahora también en G. Marini, Storicità del diritto e dignità dell'uomo, Nápoles, Morano, 1987, págs. 89-136 (100).

${ }^{27}$ Mas Hegel no se limita a parangonar a Fries con Savigny, va más allá asimilándolo a Haller. El punto del Prefacio en el que se habla del shiboleth remite a la nota del $\S 258$, donde, criticando a Haller, Hegel concluye: «El odio de la ley, del derecho legalmente determinado, es el shiboleth por el que se revelan y dan a conocer de modo indudable el fanatismo y la hipocresía de las buenas intenciones, cualquiera que sea el ropaje que vistan» (Rph § 258 A pág. 697. 25-29). Evidentemente en esta ocasión Hegel hace, por así decirlo, de cada hierba un fardo; confunde adrede derecha e izquierda, al asimilar a Fries con Savigny y Haller. 
Hegel el código no debería haber creado un sistema de leyes nuevas respecto al contenido, sino sistematizar, ordenar, contenidos jurídicos en gran parte históricamente existentes: «no se trata de hacer un sistema de nuevas leyes según su contenido, sino de conocer el contenido legal existente en su universalidad determinada, es decir, aprehenderlo de modo pensante» (Rph § 211 A pág. 657. 14-17).

Sin embargo, la centralidad de la ley y la necesidad de la codificación no deben hacer olvidar que, según Hegel, tampoco este sistema complejo de reglas consigue eliminar las contradicciones e injusticias presentes en la sociedad. El derecho deriva efectivamente de la razón, pero desciende y vive en la existencia histórica. En este transitar necesario de lo abstracto a lo concreto, del concepto a la existencia, tiene lugar una verdadera contaminación. En este darse a la existencia se halla presente como posibilidad interna, dialécticamente insuprimible, la precariedad de lo racional. La existencia de la ley no excluye, pues, un margen ineliminable de arbitrariedad y de injusticia. El código, claro está, no podrá ser «algo absolutamente determinado que no pueda admitir ninguna determinación ulterior», pero sería totalmente erróneo «a causa de que no puede llegar a esa perfección no dejarlo alcanzar lo que se llama imperfecto, es decir la realidad efectiva» (Rph § 216 a pág. 662. 25-663. 3). Lo accidental se acoge no de forma escéptica, sino racionalmente. Un sistema de leyes y códigos es necesario, aun a sabiendas de que su naturaleza finita lo conducirá a una serie de determinaciones sin fin y que, por tanto, siempre se precisarán nuevas integraciones.

Es más, incluso el sistema de leyes más perfecto no garantiza automáticamente que se haga justicia. La actividad del juez, llamado a aplicar la ley al caso particular, no escapa del peligro de una decisión, dentro de ciertos límites, accidental: «un golpe de más, un tálero o un centavo, una semana, o un día de prisión de más o de menos son una injusticia» (Rph $\S 214$ A pág. 660. 4-7).

En conclusión, Hegel critica dos posiciones antitéticas y, sin embargo, convergentes, aunque en el texto publicado el acento se ponga sobre todo en la Escuela histórica. Por un lado, la filosofía engreída del abstracto deber ser, que en materia jurídica se traduce en la petición de un código «absolutamente completo». Tal filosofía, apreciada por el intelecto, corre tras una inalcanzable perfección. Por otro lado, la Escuela histórica, que, al juzgar esta perfección inalcanzable, renuncia a la propia idea de la codificación y acepta todo lo existente con sus costumbres e instituciones. No se trata ni de enseñar al mundo cómo debe ser, ni de justificar toda institución por el mero hecho de que exista. Esta visión no permite alcanzar confortantes logros constructivos, puntos de vista a partir de los cuales probar una total refundación. No existe un mundo totalmente distinto y, 
no obstante, existen en el interior de este mundo márgenes de intervención, soluciones provisionales. Lo irracional, la injusticia, existe en la historia junto a la posibilidad de superarla:

Una importante fuente de complicación de la legislación la constituye el proceso por el cual con el tiempo lo racional, lo en y por sí jurídico, va penetrando en instituciones originales que contenían una injusticia y eran por lo tanto instituciones meramente históricas (Rph $\$ 216$ A pág. 662. 13-16).

La fe en la razón, empero, no se identifica con el optimismo en la historia. El impulso de la razón es la instancia ética que armoniza la existencia histórica y la realización del concepto. Lo racional se convierte en parámetro crítico de lo existente. En cambio, a la Escuela histórica le falta la crítica histórica, que después de Hegel será el as en la manga de los jóvenes hegelianos ${ }^{28}$.

2.4. Debería ahora aparecer con suficiente claridad el hecho de que la complejidad de la sociedad civil no se deja reducir a su relación con la economía política, sino que demanda ante todo problemas relacionados con la organización política de la sociedad. Junto a la exigencia de un derecho codificado, que defienda la propiedad y la libertad de los individuos, Hegel atribuye a esta sociedad una función esencialmente administrativa. No sólo reglas y normas jurídicas, sino también un conjunto institucional caracterizado por una destacada función de intervención administrativa. Hegel llama Polizei al conjunto de disposiciones mediante las cuales el poder público interviene en la vida económica y social con la finalidad de garantizar los intereses de la colectividad.

También respecto a la Polizei se da el mismo problema que ya aparecía a propósito de la administración de justicia. Quien ha visto en la administración de justicia una figura determinada de Estado (liberal) ha subrayado también en la Polizei una nueva figura de Estado (policial) ${ }^{29}$. Queda por preguntarse, al igual que hicimos respecto

${ }^{28}$ Quien sostendrá esta posición con mayor vigor en el ámbito del movimiento juvenil hegeliano, radicalizándola versus Hegel, es Arnold Ruge. En su ensayo tal vez más notable, publicado en el verano de 1842, «Die Hegelsche Rechtsphilosophie und die Politik unserer Zeit» (aparecido en Deutsche Jahrbücher für Wissenschaft und Kunst) se anticipan lúcidamente todos los motivos fundamentales de la posterior crítica de Marx. Cfr. al respecto P. Becchi, «Notas sobre Arnold Ruge. La interpretación política de la 'Rechtsphilosophie' hegeliana», Sistema, 49, 1982, págs. 129-140.

${ }^{29}$ Escribe Solari: «el nombre recuerda al Estado policial de la ilustración alemana, que consideraba como su principal deber contribuir al bienestar y a la felicidad interna y externa de todos los ciudadanos. Hegel no participa de la aversión de 
a la administración de justicia, si no es problemático desde el punto de vista de la construcción hegeliana considerar la sociedad como Estado, y aquí en la forma de Estado policial. De seguir aquella interpretación se concluye que en Hegel se darían al menos tres figuras de Estado. Cómo tales figuras puedan coexistir, parece destinado a seguir siendo un problema. Creo que también para este caso valen las objeciones ya vistas en relación a la administración de justicia (cfr. supra 2.2.). Es preciso insistir en que la policía, del mismo modo que la organización jurídica, es una función que Hegel atribuye a la sociedad civil y no al Estado.

El sentido de esta atribución se explica por el hecho de que lo que está en discusión no es quiénes sean los sujetos llamados a realizar tales instituciones y de quién dependen (por ejemplo, el juez o el funcionario de la administración pública). El curso de la exposición en la sección sobre la sociedad civil, como por otro lado el de toda la obra, parte más bien de la idea de desarrollo en la toma de conciencia de una voluntad libre que, en su proceder, se da siempre nuevos grados de realización de su libertad y sucesivas aproximaciones a lo universal. En el sistema de las necesidades el vínculo con lo universal se quiebra, permanece puramente «formal», adquiere una relativa existencia a nivel de la administración de justicia, pero sólo en relación a casos particulares. Por otro lado, las contradicciones sociales pueden dar origen a fenómenos que tienden a poner en peligro su propia existencia. A estos peligros se pide que responda la policía, que tiene como deber principal el de garantizar la seguridad de los sujetos sociales. Pero los deberes de la policía no se limitan a esta función esencialmente preventiva. Su apertura a lo universal hace que deba no sólo garantizar la seguridad, sino además proveer el bienestar de los sujetos sociales. Así se explica también por qué, en esta parte, Hegel dedica su atención a los problemas que afloran debido al desarrollo desenfrenado de la sociedad burguesa: miseria, pobreza, desempleo, etc. También de estas cuestiones debe ocuparse la policía. Pero tal cantidad de deberes asignados a la policía no debe hacer pensar que Hegel sea un partidario del Estado policial, por lo menos si con tal expresión se entiende algo contrapuesto al ideal liberal de un Estado de derecho. Desde esta perspectiva, su posición si acaso puede estar más cercana a la de un acreditado teórico del liberalismo alemán: Robert von Mohl. La crítica que Mohl dirige a la «concepción moderna negativa de la libertad», en la cual «el aislamiento egoísta del individuo

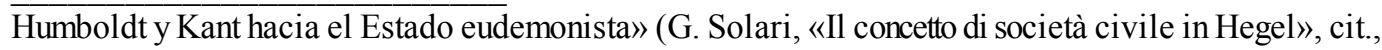
pág. 247). 
encontró su plena justificación ${ }^{30}$ constituye sin duda un punto de contacto con Hegel. A partir de esta crítica nace una valoración distinta de la función de la Polizei. Caída ésta en descrédito al inicio del siglo XIX, es rehabilitada por Mohl, para el cual vuelve a significar:

el conjunto de aquellas instituciones y ordenamiento que aspiran, con la aplicación de la fuerza pública, a remover todos los obstáculos que se oponen al desarrollo de las facultades humanas e insuperables con el simple medio de las fuerzas privadas ${ }^{31}$.

Esta definición constituye una premisa válida para superar la esfera de la administración de justicia, limitada esencialmente a la conservación y defensa de la libertad y de la propiedad de los individuos. Mohl permanece así dentro de la corriente del liberalismo alemán. Recuperará significativamente un concepto más amplio de administración, del cual forma parte fundamental la preocupación por el bienestar de los individuos.

También para Hegel la acción de la sociedad civil, de esta sociedad jurídicamente regulada y dirigida, no puede limitarse a impedir las violaciones de la propiedad, sino que debe extenderse hasta garantizar la seguridad y el bienestar de sus componentes. En especial, debe defenderlos del juego de las fuerzas accidentales que siempre perturban la vida social, de las consecuencias de acciones económicamente necesarias y jurídicamente lícitas, pero lesivas para el interés colectivo. Existen situaciones sociales que no son regulables de forma simple, sino que requieren la intervención activa de una administración pública. Aún con anterioridad a Mohl, Hegel usa el término Polizei con el fin de englobar la entera esfera de la administración,

${ }^{30}$ R. v. Mohl, Die Geschichte und Literatur der Staatswissenschaften. In Monographien dargestellt, Erlangen, F. Enke, 1855, vol. 1, págs. 242 y ss. Sobre Mohl, cfr. E. Angermann, Robert von Mohl 1799-1875. Leben und Werk eines altliberalen Staatsgelehrten, Neuwied u. Berlin, Luchterhand, 1962. En Italia ha escrito páginas significativas sobre Mohl F. M. De Sanctis, «Robert von Mohl: una critica liberale all'individualismo» (1976), ahora en Società moderna e democrazia, cit., págs. 37-57.

${ }^{31}$ R. von Mohl, Die Polizeiwissenschaft nach den Grundsätzen des Rechtsstaates, Tubinga, H. Laupp, 1832-1834 (del que he consultado la segunda edición de 1844-45), Bd. I, pág. 11. Sobre la vieja «Polizeiwissenschaft» sigue siendo fundamental H. Maier, Die altere deutsche Staats und Verwaltungslehre (Polizeiwissenschaft). Ein Beitrag zur Geschichte der politischen Wissenschaft in Deutschland, Neuwied u. Berlin, Luchterhand, 1966, Véase ahora también P. Preu, Polizeibegriff und Staatszwecklehre, Gotinga, O. Schwartz, 1983. 
rechazando una acepción más limitada, concretamente la que atribuía a la policía funciones únicamente coactivas y represivas.

La organización jurídica se refiere ante todo a la defensa y a la protección de lo que individuo posee; para la ley, en cuanto tal, el bienestar y la felicidad de los individuos es algo exterior. No obstante, este bienestar es una determinación esencial de la cual la sociedad civil debe hacerse cargo. Y cuanto mayor es la conciencia de los elementos de crisis que caracterizan el desarrollo de la sociedad capitalista, mayor es la conciencia de la necesidad de una administración pública que intervenga allí donde la simple administración de la justicia se revela insuficiente. Así, también respecto a este punto, en los cursos posteriores a la publicación de la Filosofía del derecho encontramos una mayor atención a mecanismos de defensa de la sociedad, como son la policía y la corporación.

En las lecciones de 1822/23, por ejemplo, Hegel se expresa del modo siguiente:

La justicia es algo grande en la sociedad civil. Leyes fijas y justas harán prosperar al Estado (...). Pero esto no basta. Puesto que yo estoy totalmente conectado a la particularidad, tengo el derecho de exigir que en esta conexión se favorezca también mi bienestar particular (Rph V § A pág. 690. 8-20).

En otros términos, las leyes y su pertinente ordenamiento judicial no son suficientes para garantizar el bienestar de los individuos en los conflictos de la vida económica. A esto último debe poner remedio una inteligente acción de policía. La administración de justicia se limita a impedir las violaciones de la propiedad; la administración pública aspira a garantizar la estabilidad y la seguridad social de todos.

La esfera de los intereses privados, sin ser totalmente trascendida, encuentra ya su primera reglamentación por medio de órganos públicos puestos a su servicio. La diferencia entre Estado y sociedad se halla, pues continuamente mediatizada; concretamente, la policía indica el intento de una recomposición en el medio administrativo. En cuanto poder que se ocupa de la universalidad, la policía lucha contra la incontrovertible actividad del sistema de las necesidades, la acumulación de riquezas y el empobrecimiento de una gran masa de población. No pueden establecerse confines absolutos a la intervención de la policía; sus deberes dependen de la particular situación social y política. De todos modos, es cierto que su radio de acción deber ser los suficientemente amplio como para comprender aquel conjunto de actividades que hoy llamaríamos de política económica (intervención en la economía, regulación del mercado), sin que, por otra parte, extienda su dominio a todo asunto posible. 
El mecanismo económico genera contradicciones incurables (y resulta significativo que la cima de la contradicción se alcance precisamente en los párrafos dedicados a la policía), a las que la policía debe, cuando menos, intentar responder, aun sabiendo que la dialéctica conflictual de la moderna sociedad industrial no permite hallar la síntesis que la resuelva. Sólo caben tentativas. Una de ellas merece traerse a colación. Por ejemplo, Hegel es partidario de una política rigurosa de equidad fiscal. No se trata de las tasas para indigentes ${ }^{32}$, mísero expediente con el que los ricos aparentaban generosidad frente a los pobres, sino de los impuestos en el sentido moderno de la palabra. Es éste un aspecto sobre el que Hegel insiste en las lecciones de 1824/25:

El control, las verificaciones policiales se llevan a cabo sobre todo debido a los impuestos directos que el Estado debe exigir; para evitar trampas son necesarias múltiples verificaciones y frecuentes informes. En Inglaterra la libertad personal está bien garantizada y, sin embargo, tiene al mismo tiempo las tasas más altas (...) entonces son necesarios muchos controles, investigaciones más amplias y rigurosas, que conllevan incluso la intrusión en la casas ( $R p h$ VI $\S 234$ A pág. 593. 18-27).

No obstante, ni siquiera una rigurosa política fiscal parece estar en condiciones de resolver el problema de la pobreza. La pobreza es endémica al sistema, cuyos fundamentos Hegel no pone nunca en tela de juicio. Hegel acepta la estructura económica moderna, defiende tanto la propiedad privada como la división del trabajo y acoge en su sistema la formación de una sociedad que acentúa el antagonismo, el conflicto, la laceración. Pero, a diferencia de Smith y Ricardo, Hegel no cree en una armonía espontánea de los intereses económicos en conflicto. No sin cierta ironía, polemiza contra el principio liberal del laissez aller, laissez faire:

Incluso la peste termina (...), pero cientos de miles han parecido por su causa, todos han muerto, de tal modo que todo

${ }^{32}$ Así como Hegel considera la beneficencia un residuo de la sociedad feudal, también opina que las tasas para los pobres constituyen un obstáculo para el desarrollo de la sociedad burguesa. Esta sociedad se basa en el trabajo: asegurar a los pobres una subsistencia que no esté mediada por el trabajo significa ir contra el principio informador de las nuevas relaciones sociales. Y eso que está escrito en el texto publicado ( $R p h \S 245 \mathrm{~A})$, se repite en las lecciones posteriores ( $R p h \mathrm{~V}$ pág. 703. 24-26 y pág. 704. 13-25; Rph VI pág. 611. 16-26). 
vuelve a su lugar. Si en un principio, en la policía, en el Gobierno, predominaba el afán de mandar, reina la comodidad de no ocuparse de nada (...). La seguridad de la subsistencia se ha superado mediante el principio de dejarlo todo a su aire, que las familias reciban asistencia se deja a la casualidad (Rph VI § 253 pág. 625. 19-27).

Hegel es contrario a la receta liberal, pero también se opone a una solución de crisis desde lo alto, que anule la autonomía de la sociedad civil. Es el dilema al que se enfrenta Hegel: si la sociedad se abandona a su suerte, reina el caos y la anarquía; si el Estado interviene en la sociedad de forma autoritaria y anulando la libertad que la gobierna (Estado policial), entonces desaparece la distinción entre Estado y sociedad, fundamento de su sistema. Al «animal salvaje», por tomar una conocida metáfora hegeliana, no se le abate, sino que debe sometérsele a una continua domesticación ${ }^{33}$. La economía es guiada mediante una atenta actividad administrativa, a través de intervenciones que sepan salvaguardar el interés de la colectividad sin negar, empero, la autonomía de la esfera individual con sus derechos inviolables. Si Mohl insiste en que el papel de la policía es siempre subsidiario y complementario (en la medida que no se presenta nunca como fin en sí mismo), Hegel se opone a las características «odiosas» que la policía adquiere cuando «fastidia» la vida privada. Tanto la concepción de una policía a la que compete la vigilancia de todo, como la idea de una desenfrenada libertad de los particulares deben superarse:

El individuo debe tener el derecho a ganarse su propio sustento de este o de aquel modo (...), pero, por otro lado, también lo público (Publicum) tiene el derecho a exigir que se abastezca de forma general de lo necesario $(R p h \mathrm{~V} \S 236$ A págs. 695. 32-33 y 696. 1 y 5-7).

El interés privado invoca la libertad de iniciativa frente a todo tipo de intromisión; pero cuanto más degenera el interés particular en fin egoísta, tanto mayor es la necesidad de una policía capaz de reconducir a lo universal las peligrosas convulsiones y los estímulos anárquicos de la moderna sociedad industrial.

${ }^{33}$ G. W. F. Hegel, Gesammelte Werke, Bd. 6: Jeaner Systementwürfe I. Das System der spekulativen Philosophie. Fragmente aus Vorlesungmanuskripten zur Philosophie des Natur und des Geistes. 1803/1804, hrsg. von K. Düsing u. H. Kimmerle, Hamburg, F. Meiner, 1975 (tr. it. a cargo de G. Cantillo. Filosofia dello spirito jenese, Roma-Bari, Laterza, 1984, pág. 61). 
A donde no alcanza la policía, se pide la intervención de otro nivel de organización social con deberes y competencias específicos: la corporación. La introducción de este elemento en el sistema hegeliano es más problemático de lo que pueda parecer a primera vista. Hay que notar ante todo la relevancia que el tema de las corporaciones asume en las lecciones posteriores a la publicación de la Filosofía del derecho. Es verdad que en los cursos precedentes se encuentra también este argumento, pero es significativo que el término no aparezca aún junto a la policía en el título de esta parte de la sociedad civil.

El sistema corporativo, introducido en el texto publicado con su propia autonomía respecto a los deberes de la policía, tiene esencialmente la función de estabilizar el cuerpo social, al dar al individuo la conciencia de encontrar en su seno la garantía de su subsistencia, su bienestar y, por ende, su propia dignidad: «Si no es miembro de una corporación autorizada el individuo carece de honor profesional y es reducido por su aislamiento al aspecto egoísta de la industria, en el que su subsistencia y su goce no son permanentes» (Rph § 253 A pág. 688. 27 y 629. 1-3). En la corporación el individuo supera el propio egoísmo y adquiere conciencia de un interés común, se le educa en el sentido de lo universal; es «la raíz ética del Estado, hundida en la sociedad civil» (Rph § 255 pág. 690. 4-5).

Los deberes que Hegel atribuye a las corporaciones han sido ya comparadas con las que después asumirían los partidos políticos o las organizaciones sindicales ${ }^{34}$. Ambas interpretaciones tienen su fundamento. Si se observa la corporación desde el punto de vista del Estado, el problema, totalmente político, es el de la representación, por lo que puede parecer de alguna forma justificado el llamamiento a los partidos políticos. Si, por contra, se observa la corporación desde el punto de vista de la sociedad, entonces puede parecer más convincente la llamada a los sindicatos. Por supuesto, Hegel no habla ni de partidos ni de sindicatos, si bien ambos empezaron a existir antes que sus nombres. Con todo, hay algo en estas interpretaciones que no consigue convencerme.

${ }^{34}$ La primera hipótesis ha sido avanzada por Shlomo Avineri en su libro Hegel's Theory the Modern State (1972), tr. it. de B. Maffi, La teoria hegeliana dello Stato, Roma-Bari, Laterza, 1973, pág. 196; la segunda, por D. Losurdo, Tra Hegel e Bismarck, cit., pág. 177. En general, acerca del concepto de corporación, véase la amplia investigación de F. Müller, Korporations und Assoziation. Eine Problemgeschichte der Vereinigungsfreiheit im deutschen Vormärz, Berlin, Duncker u. Humblot, 1965 (las págs. 146-219 están dedicadas a la doctrina hegeliana de las corporaciones). Sobre el tema, con especial referencia a Hegel, cfr. ahora W. Kersting, «Polizei und Korporation in Hegels Darstellung der bürgerlichen Gesellschaft», Hegel-Jahrbuch 1986, 1988, págs. 373-381. 
Hegel sin duda está muy lejos de querer resucitar la corporación medieval. Mas se erige en defensor de los privilegios y de los particularismos de las corporaciones feudales. Las antiguas corporaciones obstaculizan el desarrollo económico: al suprimirse, el individuo -aunque con condicionamientos- será libre de elegir su profesión. Por otro lado, dado el papel que Hegel atribuye a las corporaciones, no cabe en ningún caso que la autoridad de éstas se oponga a la del Estado.

Lo anterior no requiere muchas explicaciones: la libre elección de profesión es un principio fundamental del mundo moderno ( $§ 206)$ y la corporación, cuando, como en el pasado, quiere autoafirmarse, «puede incluso resultar peligrosa para la totalidad del Estado» (Rph VI $§ 255$ A pág. 628. 29-30). Y, no obstante, Hegel percibe lúcidamente y de inmediato el reverso de la medalla:

Que cada miembro tenga el derecho a ganarse la subsistencia a través de su habilidad no puede ponerse en discusión de forma abstracta, pero lo que inmediatamente se encuentra ligado a esto es lo siguiente. El individuo quiere hacer lo que está en condiciones de hacer y la elección le compete, se basa en su arbitrio; la otra cara [empero] es que el individuo no sólo quiere hacer lo que está en condiciones de hacer, sino que tiene el objetivo esencial de que mediante esto se le garantice su subsistencia (Rph Vi § 254 A pág. 624. 15-21).

Si la libertad profesional, además, significa la libertad para estar desempleado, el individuo no sabe qué hacer con ella. El hombre, en efecto, trabaja para garantizar su propia subsistencia y la de su familia, pero no por el placer de trabajar. Una libertad laboral que no esté en condiciones de alcanzar este objetivo es meramente abstracta y formal. Aquí interviene la necesidad de una organización del trabajo ocupada en garantizar a todos la subsistencia. Y Hegel no encuentra una mejor expresión que el término «corporación»:

Generalmente uno se detiene en el lado formal del hacer lo que se quiere, mientras lo esencial está en el otro lado, que el objetivo [de la subsistencia] se alcance y esto es lo que hace la corporación. Nadie arroja al agua por la noche los productos de su jornada de trabajo, ya que éstos son su finalidad; no lo es su trabajo, que es sólo el medio, sino el resultado, la satisfacción de sus necesidades, el sustento asegurado (Rph VI §254 A pág. 624. 24-30).

Hegel sabe perfectamente que en su época el término «corporación» es «la expresión más difamada, en especial por los franceses 
que desde la época de la revolución odian la corporación y los privilegios» (Rph VI $\S 250$ A pág. 618. 12-14). Pero también sabe muy bien que la implacable dialéctica económica liberada por la revolución ha reducido el espíritu de comunidad al polvo de los individuos. Si bien es cierto que alguna vez usa términos tales como "Genossenschaft» (por ejemplo, Rph § 251), «Organization» (por ejemplo, Rph V § 254 pág. 713. 11), «Gewerbe, Zunft» (por ejemplo, Rph V $\$ 251$ pág. 621. 16-17) ${ }^{35}$, normalmente no encuentra un nombre mejor que «Korporation» para designar una institución que haga del principio de solidaridad su eje. La corporación es, según Hegel, la organización más idónea para defender los intereses del estamento industrial y garantizar a sus miembros asistencia y solidaridad en caso de necesidad. Pero sobre este punto hay que precisar rápidamente que el argumento de Hegel tiene que ver con la clase industrial en su conjunto. En otras palabras, la corporación agrupa en asociaciones comunes a trabajadores y empresarios. Es una cuestión sobre la cual Hegel no varía su opinión. No está en discusión -como recientemente se ha sostenido- el derecho de «los obreros a asociarse ${ }^{36}$, sino el derecho de la industria en su conjunto a continuar

${ }^{35}$ Losurdo introduce una distinción entre Zunft y Korporation que no encuentra apoyo en los textos de Hegel. Escribe que el término Zunft sigue siendo utilizado «siempre para designar corporaciones feudales. Está claro que, en el texto hegeliano, Zunft y Korporation indican dos realidades y dos problemáticas totalmente distintas» (D. Losurdo, Tra Hegel e Bismarck, cit., págs. 176-177). A mí no me lo parece. En las lecciones de 1824/25 Hegel dice: «Die Korporation ist zunächst vorzustellen als Gemeinde und näher als Gewerbe, Zunft» (Rph VI § 251 pág. 621. 16-17).

${ }^{36}$ En este sentido, D. Losurdo, Tra Hegel e Bismarck, cit., pág. 182. Después de citar un pasaje de las lecciones, Losurdo aún de forma más radical concluye: «Llegados a este punto no hay equívoco posible: al teorizar la necesidad de la 'corporación' Hegel reivindica el derecho de asociación para un clase social bien determinada» (183). Pero veamos el paso en el que se basa esta interpretación. Lo cito por entero porque sólo así puede comprenderse lo que quiere decir Hegel: «Hace algunos años, el gobierno francés realizó una investigación acerca de los avances de la industria; las cámaras de comercio respondieron que el comercio florece en mayor medida desde que se han suprimido las corporaciones. Pero el comercio aumenta sus ganancias cuando más mísera es la clase trabajadora (arbeitende Klasse), cuando ésta trabaja más barato, y el comerciante puede vender a mejor precio. Pero las obras de la industria empeoran con la supresión de las corporaciones» (Rph V § 254 A pág. 712. 1-15). Está claro que, si se saca de contexto la imagen de la clase trabajadora que trabaja barato, se puede llegar quizá a la conclusión de que Hegel pensaba en la organización de la clase obrera. Pero siguiendo íntegramente el paso citado se llega a una conclusión bien distinta. Hegel discute aquí los resultados de una investigación promovida por el gobierno francés que habría demostrado lo dañina que resultaba la corporación para el desarrollo del comercio. Hegel no discute este hecho, pero observa (seguramente sobre la base de la misma fuente) que respecto a la actividad industrial había sucedido lo opuesto. Es un modo de insistir, bajo la base 
organizándose 
en corporaciones. Las nuevas formas de asociación obrera se basan en el conflicto de intereses, en la lucha de clases. A Hegel no se le oculta la realidad de los conflictos surgidos con el desarrollo de la sociedad industrial. Sin embargo, no percibe que, precisamente de tales conflictos, está naciendo un nuevo sujeto social portador de valores autónomos. Resulta significativo que al respecto hable a menudo de plebe (Pöbel) ${ }^{37}$ y que ésta no tenga una autonomía propia en la dialéctica de los grupos (cfr. $R p h \S 244)$. Hegel, que seguía con gran atención el desarrollo de la industria en Inglaterra, en un apunte berlinés escribe acerca de los «excesos de la plebe inglesa» que destruye las «máquinas de vapor» ${ }^{38}$. Es clara la referencia al movimiento ludita, que se repite en las lecciones de $1822 / 23$ y $1824 / 253^{39}$. No obstante, Hegel se limita únicamente a registrar estos hechos: intuye la realidad de una nueva clase social, pero no la conceptualiza. De ahí la imagen de una clase industrial organizada en corporacione, es decir, de forma interclasista: en ella no domina la lucha de clases, sino la colaboración entre ellas. ¡Hegel no es Marx! No por ello hay que inscribir a Hegel entre los teóricos de la reacción feudal o asimilarlo a los escritores políticos conservadores. Igual visión interclasista teoriza Saint-Simon en Francia por los mismos años y en una obra que el propio Hegel cita a menudo en las lecciones de 1824/25: el Catéchisme des industriels publicado hacía poco ${ }^{40}$. Encontramos aquí de nuevo la misma mezcla de adversarios sociales dentro del estamento industrial. ¡Hegel, después de todo, no se encontraba en tan mala compañía! Mas no pretendo insistir sobre esta cuestión ${ }^{41}$.

de los datos de una encuesta reciente, en las ventajas que tendría en cambio una organización corporativa de la industria. Cuando aquí Hegel habla de «clase trabajadora» es evidente que no está pensando en el proletariado contrapuesto a los capitalistas, sino en el estamento industrial en su conjunto contrapuesto a los intereses del estamento comercial. No estaba en discusión el derecho de los obreros a formar sindicatos, sino el de la industria a organizarse en corporaciones.

${ }^{40}$ C. H. de Saint-Simon, Cathéchisme des industriels (1823/24). [Tr. cast. parcial de Carlos Melchor y Leopoldo Rodríguez: «Catecismo de los industriales», en G. Ionescu (ed.), El pensamiento político de Saint-Simon, México. F.C.E., 1983. págs. 200-223]. La referencia implícita a Saint-Simon se encuentra en el curso de 1824/25, cuando Hegel escribe que considera excesivo que «en el cathéchisme industriel, la nation industrielle se tome como la única y los demás estamentos se consideren sólo sus funcionarios, sus servidores» (Rph VI § 204 pág. 520. 6-9). Heggel comparte con Saint-Simon la idea de que el «estamento industrial» es «el estamento principal de la sociedad civil» (Rph VI § 204 pág. 519. 18-19), pero le parece también importante para el buen funcionamiento de la sociedad la presencia de una buena administración y de una eficiente burocracia. Por otro lado, mientras Saint-Simon considera sólo el aspecto positivo del trabajo y de la industria, Hegel -como se ha visto- tiene siempre en cuenta la otra cara de la moneda.

${ }^{41}$ Sobre Hegel y Saint-Simon véanse en especial las referencias contenidas en 
En resumen, lo relevante en la imagen que Hegel nos presenta de la sociedad civil no son los medios que propone para organizarla; lo que importa en su caracterización no simplemente como sistema económico, sino como conjunto de sistemas y centros de valor sobre los cuales se asienta la modernidad. Es este último punto el que ahora hay que considerar.

\section{Dialéctica y crítica de la sociedad civil}

3. 1. En la observación al $\S 209$, donde empieza la parte dedicada a la administración de justicia, Hegel afirma:

Pertenece a la cultura, al pensar como conciencia del individuo en la forma de la universalidad, que yo sea aprehendido como persona universal, en lo cual todos somos idénticos. El hombre vale porque es hombre y no porque sea judío, católico, protestante, alemán, italiano. (Rph § 209 A pág. 654. 8-12).

Es la esfera de la sociedad civil, al nivel del sistema de leyes, reaparece el horizonte problemático que se encuentra al nivel del derecho abstracto. No hay una línea directa que proceda de la sociedad al Estado, sino una compleja red de interferencias que proviene del derecho abstracto, pasa a través de la moralidad y alcanza el derecho en la sociedad civil.

¿Qué hilo une estas fases particulares en el desarrollo sistemático? El fundamento del derecho es la radical reivindicación de la libertad del sujeto. Los hombres son distintos en cuanto a su particular situación social y cualidad natural, pero esta diversidad no pertenece a la abstracta determinación según la cual cada uno debe ser considerado un ser libre, una persona: «trata y respeta a los demás como personas» (Rph § 36), escribe Hegel, formulando en términos kantianos el supremo precepto jurídico. Hegel parece moverse dentro del mismo ámbito categorial de la tradición kantiana. La propia materia que Kant había presentado como derecho privado en la Metafísica de las costumbres aparece aquí como derecho abstracto. Hegel concuerda con Kant al sostener que el hombre es ante todo sujeto de derechos. Todas las normas jurídicas derivan de esta norma

dos ensayos de J. D’Hondt, «Hegel et les socialistes» (1971), en De Hegel à Marx, París, Puf, 1972, págs. 164-191 [tr. cast.: De Hegel a Marx, Buenos Aires, Amorrortu 1974] y «Hegel et le socialisme naissant: la misère dans l'abondance», Rivista di filosofia, 1977, págs. 49-74 (tr. it. 75-94). 
fundamental: al hombre, en primer lugar, hay que reconocerlo como sujeto de derechos y él, a su vez, debe reconocer en los demás esta misma cualidad. Con el fin de desarrollar esta idea, Hegel se sirve del método consistente en abstraer todas las condiciones de convivencia creadas por los hombres. El fondo del análisis, pues, es una ficción, la del estado de naturaleza (si bien Hegel no lo dice de forma expresa), sin relaciones sociales estables. Con el fin de reclamar la atención sobre esta «ficción metodológica», Hegel habla de derecho abstracto $^{42}$.

Parece acogerse aquí, en aparente contradicción con el significado general de su sistema, la ficción del derecho natural moderno mediante la cual cabe concebir un derecho personal y una relación de propiedad sin el presupuesto de la sociedad y el Estado. Ciertamente, si el punto de partida es esta concepción del derecho abstracto concretado al nivel de las conexiones que unen a Hegel con el derecho natural moderno. En efecto, Hegel, a ese nivel, acepta dos aspectos fundamentales de aquella doctrina: a) la idea liberal de la defensa y de la seguridad de la vida privada; b) la proclamación de la libertad subjetiva como cambio y punto central de la «libertad de los modernos».

El primer aspecto ya ha sido recordado al analizar los distintos momentos que componen la sociedad civil. Ahora toca decir algo respecto al segundo. Este último aspecto impregna toda su obra. Hegel introduce, así, en el ámbito de lo ético el pensamiento moderno de la libertad individual: ningún clasicismo puede ya ocultar el radical reconocimiento del «valor infinito» de la individualidad humana. El carácter inmediato del ethos se disuelve en una multiplicidad de individuos que reivindican su libertad: «El derecho de la particularidad del sujeto a encontrarse satisfecho, o, lo que es lo mismo, el derecho de la libertad subjetiva constituye el punto central y de transición en la diferencia entre la antigüedad y la época moderna» (Rph $\S 124$ A pág. 446. 20-25). Creer que es posible conciliar en un único acto las distintas escenas de la libertad es la ilusión, el rito mágico de una imposible nueva $\mathrm{Grecia}^{43}$. Esta utopía redentora, esta fe en una suprema armonía, genera al verdugo, conduce al terror. En la antigüedad, el individuo no poseía una esfera de derecho propia que oponer al Estado. Los antiguos no conocían este págs. 7 y 17.

${ }^{42}$ Sobre el significado de esta «ficción metodológica», cfr. K.-H. Ilting, Hegel diverso, cit.,

${ }^{43}$ Retomo aquí algunos temas de un trabajo anterior: P. Becchi, «Identità e differenze nel concetto hegeliano di società civile. L'impossibile nuova Grecia e il suo ebreo», Materiali per una storia della cultura giuridica, XI (1981), 1, págs. 47-86. 
valor, porque la libertad civil se identificaba con la libertad política. En varios lugares de la Filosofía del derecho se insiste en este extremo.

Por ejemplo, en la observación al $\S 185$, Hegel, escribe:

Platón expone en su República la eticidad sustancial en su belleza y verdad ideales, pero no pudo dar cuenta del principio de la particularidad independiente que había irrumpido en su época en la eticidad griega. (Rph § 185 A pág. 635. 17-22).

La idea de que el individuo sólo adquiere valor en la medida en que forma parte de un organismo político traía consigo el desconocimiento del sujeto y de su libertad. El interés público, la sustancialidad del ethos, absorbía el interés privado. El Estado antiguo ignoró la vida interior y las exigencias de la conciencia, infravaloró la personalidad moral y jurídica del hombre.

El reconocimiento de la personalidad jurídica, el hecho de que el hombre como tal sea sujeto de derecho, es una conquista reciente. Pertenece al mundo moderno, el cual asigna por primera vez su derecho a todas las determinaciones, se presenta como «descubrimiento» de la sociedad civil. La proclamación del valor de ser infinito, que todo individuo posee en la condición moderna, encuentra su satisfacción real, su lugar específico, en la sociedad civil. Y es precisamente en el corazón de ésta donde se advierte el latido vital de la individualidad. En su centro se recoge el hilo a través del cual se articula la libertad del sujeto. Aquí se revela aquel movimiento subterráneo, no visible de forma inmediata, que desde el derecho abstracto, pasando por la moralidad, conduce en la sociedad civil al derecho concreto. Lo cual significa que tal principio debe configurar no sólo las conciencias, sino además todo el modo de vivir y pensar de los hombres. Es preciso que este principio forme epocalmente el espíritu en todos sus momentos:

A su más precisa configuración pertenecen el amor, lo romántico, el fin de la eterna bienaventuranza del individuo, etcétera, así como la moralidad y la conciencia moral, y también las demás formas que aparecerán posteriormente como principios de la sociedad civil y como momentos de la constitución política o bien que se manifiestan en general en la historia, especialmente en la historia del arte, de las ciencias y de la filosofía ( $R p h \S 124$ A pág. 446.35 y pág. 448. 1-8).

El principio de la libre personalidad infinita aparece ya con el cristianismo, pero ha habido que esperar mucho tiempo para que se encarnase en la historia y se hiciera realmente eficaz. El espíritu emplea tiempo para progresar en su autoconciencia. 
Hace ya un millar y medio de años que la libertad de la persona ha comenzado a florecer gracias al cristianismo y ha devenido un principio universal para una parte, por lo demás pequeña, del género humano. Pero la libertad de la propiedad se podría decir que es reconocida como principio sólo desde ayer y en pocas partes. La historia universal de así un ejemplo del tiempo que necesita el espíritu para progresar en su autoconciencia (...) (Rph $\S 62$ A págs. 260. 8-15).

El valor que cada individuo posee de ser libre se realiza, pues sólo en la moderna sociedad fundada en el derecho, a primera vista podría parecer que el principio de la libertad personal no es del todo universal, que este valor no es para nada infinito, dado que es un resultado contingente, relativo a una época histórica. Ello es debido al hecho de que para que un valor sea universal debería estar presente en toda sociedad. Pero lo decisivo es que la universalidad de un valor no decae a pesar de que no se haya reconocido en todo tiempo y lugar. La universalidad de un valor requiere un acontecer mediante el cual alcance su realización. Ha sido necesario un largo proceso histórico para llevar a su pleno reconocimiento el valor de la libertad personal. Se trata de la historia y el destino de occidente concentrados en varios eslabones: desde el mundo antiguo al cristianismo, pasando por el mundo romano, hasta alcanzar aquel movimiento de regeneración del espíritu que triunfa con la reforma. Será preciso ver si esos eslabones conseguirán soldarse en una misma cadena. La dificultad se percibe de inmediato: en el camino a lo largo del cual se articula la libertad del sujeto se introduce el desarrollo incontrolado del capital. El principio del que nace el mundo moderno trae consigo las laceraciones incurables de la sociedad burguesa. Hegel es plenamente consciente de ello, pero no puede ocultar que tras las tensiones opera una «fuerza motriz» de la cual ninguna futura comunidad humana podrá ya prescindir.

3.2. El procedimiento dialéctico remite a un clásico problema que ha atormentado a todos los intérpretes desde los tiempos de Schelling y de Trendelenburg: la cuestión, eminentemente filosófica, del «comienzo»" ${ }^{44}$ Es hora de ascender a la región lógica, una altura en la que se respira un aire particularmente frío.

${ }^{44}$ F. W. J. Schelling, Münchener Vorlesungen. Zur Geschichte der neueren Philosophie, in Werke, a cargo de M. Chröter, Beek, Munich, 1928, vol. V, pág. 223 (tr. it de G. Durante, Lezioni monachesi sulla storia della filosofia moderna, Turín. Giappichelli, 1981, reimpresión anastática autorizada por la Editorial Sansoni, págs. 180 y ss.); A. Trendelenburg, Logische Untersuchungen, Berlin, G. Bethge, vol. II, págs. 344 y ss. 
En la Filosofía del derecho encontramos la sucesión derecho-moralidad-eticidad (y dentro de la eticidad: familia-sociedad civil-Estado). Pero la última figura de las dos sucesiones no es un posterius, sino un prius respecto a las figuras anteriores. En las lecciones de 1822/23 Hegel se expresa así:

Lo real para nosotros está en tercer lugar, a pesar de que, según la realidad, sea lo primero. Así, formalmente la familia es anterior a la propiedad, al delito, etc. Igualmente, el Estado es anterior a la moralidad (Rph V § 32 A pág. 169. 26-34).

¿Por qué esta complicación adicional? ¿Por qué en apariencia la sociedad es anterior al Estado, pero en realidad el Estado es anterior a la sociedad? ¿Por qué el Estado "asigna» la multitud de individuos a las figuras inferiores de la familia y de la sociedad en vez de «proceder» de éstas? En suma, ¿por qué el concepto precede a sus determinaciones? El nudo es resistente. Probó a desatarlo el joven Marx. En su discusión del $§ 262$ criticaba aquella idea real, el Estado, que «se divide a sí mismo» en las esferas ideales de su concepto (la familia y la sociedad) y «asigna a tales esferas los individuos en cuanto multitud». Objetaba, por el contrario, que «el Estado procede de la multitud, en tanto en cuanto ésta existe como conjunto de miembros de la familia y de la sociedad civil» y concluía que «la especulación enuncia este hecho, esta relación real, como apariencia, como un fenómeno ${ }^{45}$. No me interesa retomar la célebre polémica ${ }^{46}$, pero es sintomático que más allá de las inciertas y débiles soluciones que ofrece Marx las anteriores preguntas parezcan aún dignas de formularse.

En un agregado a la Enciclopedia hay un largo pasaje que se refiere de forma expresa a la Filosofía del Derecho. Vale la pena transcribirlo por entero porque tal vez sea ahí donde Hegel intente responder a aquellas cuestiones:

${ }^{45}$ Marx, Aus der Kritik der Hegelschen Rechtsphilosophie. Kritik des Hegelschen Staatsrechts (§ 261-313) (1843). [Hay tr. cast. de José María Ripalda: «Crítica de la filosofía del Estado de Hegel» en Manuscritos de París. Escritos de los «Anuarios Francoalemanes», OME-5, Barcelona, Grijalbo, 1978, págs. 2-157].

${ }^{46}$ Remito tan sólo a dos contribuciones recientes: G. Marini, «Tra due secolarizzazioni: il 'mistero della filosofia hegeliana' e la critica di Marx al $§ 262$ della Filosofia del diritto», en Cristianesimo, secolarizzazione e diritto moderno, ed. a cargo de L. Lombardi Valluari y G. Dilcher, Milán y Baden-Baden, Giuffré y Nomos, 1981, págs. 369-405; R. Romano, Il compimento del soggettivismo come prassi democratica ed estinzione del diritto. Interpretazione della «Critica della filosofia hegeliana del diritto pubblico» di Marx, Milán, Giuffré, 1981. 
También en esta ciencia [la Filosofía del derecho] se empieza por algo abstracto -es decir, con el concepto de voluntad-, se progresa luego de la realización de la voluntad todavía abstracta -que se realiza en una existencia exterior- a la esfera del derecho formal; además, se procede a la voluntad -a partir de la existencia externa reflejada en sí misma- al terreno de la moralidad y se llega, en tercer lugar, a la voluntad ética que reúne en sí misma estos dos momentos abstractos y es, por consiguiente, concreta. En la propia esfera de la eticidad se empieza de nuevo a partir de lo inmediato, de la forma natural, confusa, que el espíritu tiene en la familia, de ahí se pasa a la división de la sustancia ética que se verifica en la sociedad civil, y se alcanza, por último, la unidad y verdad de esas dos formas unilaterales del espíritu ético que existen en el Estado. De ese modo de proceder de nuestro tratamiento no se sigue en absoluto que transformemos la eticidad en algo que -según el orden temporal- sea posterior al derecho y a la moralidad o que queramos postular que la familia y la sociedad civil preceden al Estado. Sabemos muy bien que la eticidad es la base del derecho y de la moralidad, así como la familia y la sociedad civil -con sus distinciones bien ordenadas- ya presuponen la existencia del Estado. Sin embargo, en el desarrollo filosófico de lo ético, no podemos empezar con el Estado, porque en él lo ético se desarrolla hasta su forma más concreta; el inicio es necesariamente algo abstracto $^{47}$.

En este pasaje, Hegel discute su propio modo de proceder, el método expositivo adecuado al desarrollo del concepto. Este método no es aplicable sólo a un fenómeno particular, sino que es realmente adecuado a la naturaleza del espíritu en sí, también a la ciencia filosófica del derecho. La exposición procede de lo abstracto a lo concreto, si bien lo concreto (la eticidad) sea -en cierto sentido- lo más profundo, el fundamento de lo abstracto. Por tanto, lo concreto es ulterior, aunque en realidad sea previo. Lo abstracto -lo que se expone en primer lugar- es, pues, en realidad posterior; es algo fundado, que tiene antes que él, como su base, lo concreto. Por este motivo, el derecho abstracto se expone en la primera parte, haciendo abstracción de todas las condiciones sociales y políticas existentes, a fin de

${ }^{47}$ G. W. F. Hegel, Sämtliche Werke, cit., Bd. 10, págs. 217 y ss., § 408 7. Como es sabido, los agregados no aparecen en la edición italiana de la Enciclopedia traducida al italiano por Croce. La reciente edición, a cargo de V. Verra, contiene los agregados, si bien hasta ahora sólo la luz el volumen relativo a la Lógica. 
reconocer ante todo lo particular, la persona con sus derechos imprescindibles. Pero es evidente que en realidad no existe nunca un hombre aislado y que sus derechos están ya inscritos en el ámbito de la comunidad. Así, pues, lo concreto, expuesto con posterioridad, en realidad es anterior, mientras que el Estado no es un posterius, sino un prius respecto a las esferas inferiores. En la exposición, la sucesión de lo concreto a lo abstracto se presenta en términos invertidos, por lo cual sólo al final aparece aquello que está desde el inicio.

El camino de lo abstracto a lo concreto es, pues, sólo aparente, porque presupone lo que sigue: los grados del desarrollo vienen precedidos idealmente por la totalidad que los contiene. Se trata, en definitiva, de un camino ideal, lógico e invertido, que procede volviendo atrás, al fundamento. Esta compleja modalidad de proceder es adecuada a la naturaleza ideal del espíritu. Hay una dialéctica del espíritu que opera idealmente en sí, antes de su ingreso en el tiempo. Esta dialéctica expresa un depliegue de grados a partir de un germen (lógico) que los implica.

La complicación nace cuando la dialéctica ideal que procede de lo concreto a lo abstracto -un procedimiento que en la exposición se presenta en términos invertidos, por lo que sólo al final aparece la complejidad del movimiento- se transfiere, se traslada de forma arbitraria, a la dialéctica real del espíritu que ingresa en el tiempo. Se presta a confusión cuando Hegel, en vez de limitarse a entender esta precedencia de lo concreto como algo puramente «ideal», supone que es también «temporal». De ahí que parezca verdaderamente que el Estado precede -según el orden temporal- a la familia, cuando, por el contrario, cabe que exista familia sin Estado.

En el orden lógico, el Estado precede a los individuos y a las familias, así como el todo precede a las partes. Pero en el orden temporal, la parte, o sea los individuos y las familias, preceden al todo, al Estado. En la dialéctica ideal, el movimiento consiste en un proceso que va de grados más abstractos a otros cada vez más concretos, con la conciencia de que estos últimos están ya contenidos en potencia en los primeros de donde deriva que ya en la determinación abstracta existe el grado más concreto. Así, el Estado ya se halla contenido en potencia en la sociedad (precisamente en los momentos de la justicia y de la policía); es más, nace de ella, aun cuando Hegel no lo diga expresamente o hasta dé a entender lo opuesto. El desarrollo que presenta la exposición es un desarrollo ideal que describe de forma invertida, a partir de lo abstracto, el proceso ideal de las determinaciones del espíritu. No se trata, pues, de un desarrollo temporal de lo que es anterior y de lo que es posterior, y no puede decirse ni siquiera que lo que en apariencia es posterior en realidad sea anterior. Dando a esta precedencia un carácter no sólo ideal sino también 
temporal, Hegel corre el riesgo de confundir la sucesión ideal con la temporal, la especulación con lo empírico. En esta trasposición está efectivamente presente el peligro de tratar la historia de manera especulativa. Los términos del movimiento aparecen realmente invertidos: el proceder desde el sujeto al Estado, del derecho abstracto a la eticidad, es sólo aparente, una ficción metodológica. En realidad, según Hegel, sucede lo opuesto: del Estado al sujeto, de lo ético al derecho. La meta es el origen.

¿Por qué Hegel invierte los términos del movimiento? ¿Por qué considera el final como el verdadero principio? ¿Por qué al comienzo es el todo y no las partes? En lo profundo de este proceder hay un residuo aristotélico que también se ha puesto de manifiesto en el pasaje de Marx citado al inicio de este trabajo (cfr. supra, pág. 6). Este residuo es difícilmente con el arranque individualista de las modernas doctrinas iusnaturalistas.

No es cierto -quede bien claro- que la dimensión del sujeto se sacrifique en el altar del Estado (como toda una tradición interpretativa desearía) ${ }^{48}$, pero tampoco lo es que sea esa subjetividad la que produzca linealmente el Estado. La tensión entre el sujeto y el Estado nunca parece resolverse adecuadamente. Cuando se enfatiza la efectualidad de la síntesis hegeliana, se pierde de vista el hecho de que la dialéctica que da origen a la forma-Estado queda, por así decirlo, en el aire. En cambio, si se acepta como criterio interpretativo la alternativa organicismo versus atomismo, estalinismo contra individualismo, se corre el riesgo de entrar en un callejón sin salida. Hegel aparece entonces, una vez más, como el teórico del Estado «orgánico» y el enemigo de la libertad individual ${ }^{49}$. Pero la unidad del Estado es para Hegel la del Leviatán: deriva de la difícil armonía de muchas particularidades independientes ${ }^{50}$.

${ }^{48}$ En este sentido, la célebre obra de K. Popper, The Open Society and Its Enemies (1951). [Hay tr. cast. de Eduardo Loedel: La sociedad abierta y sus enemigos, Buenos Aires, Paidós, 1981]. En la misma línea interpretativa. E. Topitsche, Die Sozialphilosophie Hegels als Heilslehre und Herrschaftsideologie, Neuwied u. Berlin, Luchterhand, 1967 y H. Kiesewetter, Von Hegel zu Hitler, Hamburgo, Hoffman und Campe, 1974.

${ }^{49} \mathrm{Me}$ parece que corren un riesgo de este tipo los trabajos más recientes de N. Bobbio, cfr. en especial, «Diritto privato e diritto pubblico in Hegel» (1977), ahora en Studi hegeliani, cit., págs. 85-114. También las lecciones impartidas por Bobbio sobre «Hegel y el Estado» en el Instituto Italiano per gli Studi Filosofici (Nápoles, 19-24 abril 1982) iban en esta dirección. Véase al respecto P. Becchi, «Del individuo y del Estado (Anotaciones a unas lecciones de Norberto Bobbio sobre «Hegel y el Estado»), Revista de Estudios Políticos, 44 (1985), págs. 125-135.

${ }^{50} \mathrm{Creo}$ que van en este sentido algunas observaciones sobre la relación sociedad-Estado que se encuentran en un estimulante artículo de K. Hartmann. «Idee zu 
El principio de los Estados modernos tiene la enorme fuerza y profundidad de dejar que el principio de la subjetividad se consume hasta llegar al extremo independiente de la particularidad personal, para el mismo tiempo retraerlo a su unidad sustancial, conservando así a ésta en aquel principio mismo (Rph $§ 260$ pág. 701. 27-29 y pág. 702. 1-3).

El poder del Estado no debe extenderse hasta el punto de cancelar los límites entre Estado y sociedad, y, con ellos, la libertad del sujeto. Parafraseando a Carl Schmitt, el Estado hegeliano no es «neutral», ni siquiera «total» ${ }^{51}$. Un Estado de este tipo está demasiado penetrado por los caracteres de la sociedad civil para ser aquella realidad absorbente que viejas y nuevas teorías se empeñan en ver en él.

3.3. A los ojos de Hegel, la sociedad civil se muestra como un mundo complejo, gobernado por valores específicos, que se ha intentado explorar en toda su amplitud de significado y en sus relaciones histórico-conceptuales. Es el mundo de la laboriosidad burguesa, pero también el de las libertades individuales, regulado por el derecho, garantizado por la policía. En su centro, donde se retorna la línea subterránea que proviene del derecho abstracto, reaparece concretamente realizado el valor infinito de la libertad subjetiva.

Cambiar este centro por lo periférico y colocar como base del entramado el sistema de las necesidades es el signo de aquella dialéctica negativa que haría su aparición dentro de poco en la escena histórica. De Hegel a Marx, el hilo que une en la expresión alemana «bürgerliche Gesellschaft» lo «civil» con lo «burgués», se rompe por la parte del bourgeois. «Burgués» ya no significa una clave universal, o mejor, la vida del homo aeconomicus, sino una clase particular, portadora de valores que ya no son universalizables. En Marx la sociedad civil se manifestará cada vez menos civil y más burguesa. La complejidad se reduce. Lo particular en su valor infinito es sólo la máscara tras la cual se esconde el patrón que explota. Todo se reduce a la mitad, se devalúa. La riqueza de valores de la sociedad civil hegeliana se desvanece. Cae toda tensión, la contradicción se resuelve. Pero ¿a qué precio? Focalizando todo odio sobre lo «judío»

einen neuen systematische Verständnis der hegelscher Rechtsphilosophie», Perspektiven der Philosophie, Bd. 2-1976, págs. 167-200. Del mismo autor cfr. también «Handlungstheorien im Politischen II. Teil», Perspektiven der Philosophie, Bd. 11-1985, págs. 339-347.

${ }^{51}$ C. Schmitt, Der Begriff des Politischen (texto de 1932). [Hay tr. cast. en ed. preparada por José Arico del texto de 1939: El concepto de lo político, Buenos Aires, Folio, 1984, págs. 83-84]. 
¿no se corre el riesgo de eliminar también aquel minimum irreductible de libertad subjetiva?

Precisamente en La Cuestión judía se abre la vía a este engañoso camino. En este breve aunque denso ensayo se muestra en toda su amplitud el desplome y la desapreciación de los valores. El dinero se convierte en el Dios celoso de Israel. El valor universal de lo particular esconde la realidad del valor de cambio. ¿Radicalización o reducción? ¿Profundización o empobrecimiento? La sociedad civil pasa a ser el espacio de las relaciones económicas destinadas a comprender tan sólo la insensible laboriosidad del bourgeois. Surge como una sociedad de animales intercambiadores, cuyos miembros shmithianamente no confían en ninguna mediación que no pase a través de la propia ventaja egoísta. En esta sociedad, el hombre, aun antes de ser sujeto de derecho, es objeto de sus necesidades y considerar a los demás hombres como medios para satisfacer su vida egoísta.

Desde este limitado punto de vista, la sociedad civil aparece constituida por «individuos independientes», apolíticos, e integrada por relaciones caracterizadas por un «movimiento desenfrenado» hacia el «mundo de las necesidades» $\mathrm{y}$ «del trabajo» ${ }^{52}$. En su conjunto, la falta de distinción entre sistema de las necesidades y sociedad civil reduce el significado positivo de esta última al surgimiento de la economía como instancia autónoma. La difícil coexistencia de momentos distintos que caracterizaba el argumento de Hegel se ha perdido irremediablemente. El mundo cristiano de las particularidades es sólo el mundo del egoísmo económico ${ }^{53}$. No hay espacio en esta sociedad de las necesidades para el reino del derecho con sus libertades individuales. Las libertades no son más que el reconocimiento oficial de la falsa universalidad de la sociedad burguesa: «los droits de l'homme (...) no son otra cosa que los derechos del miembro de la sociedad civil, es decir, del hombre egoísta, separado del hombre y de la Gemeinwesen ${ }^{54}$. La crítica engañosa de Marx hacia los derechos del hombre, una verdadera contradeclaración, nace de aquella interpretación deformadora del significado originario civil hegeliana.

Todo lo determina la producción material. Por esa razón, Marx da siempre mayor importancia al momento económico. Las diversas

${ }^{52}$ K. Marx, Zur Judenfrage [tr. cast. cit., pág. 199].

${ }^{53}$ Ibíd., [tr. cast. cit., págs. 206-207]: «Sólo bajo el dominio del cristianismo, que convierte en extrínsecas al hombre todas las circunstancias nacionales, naturales, éticas, teóricas, podía separarse totalmente la sociedad burguesa de la vida del Estado, desgarrar todos los vínculos que unen la especie humana, substituirlos por las apetencias del propio egoísmo y disolver el mundo de los hombres en un mundo de individuos atomizados, enfrentados hostilmente».

${ }^{54}$ Ibíd. [tr. cast. cit., pág. 195]. 
formas de la existencia se comprenden fuera de su especificidad, no son más que «modos particulares de producción», reconducibles al núcleo esencial del capital, a su vasto metabolismo capaz de engullirlo todo. El espacio del ser-en-el-mundo se llena de forma técnico-productiva. De ahí que el hombre productor y trabajador (el proletariado, la clase universal) se eleve a sujeto de la futura transformación del mundo. Marx piensa que la liberación de las fuerzas productivas mediante la revolución de una clase (por definición, sin Estado), que elimine los vínculos puestos por las relaciones de producción, conducirá a la superación de la sociedad burguesa y a la afirmación de una verdadera comunidad humana. Esta visión reforzaba su obra. Hoy, en cambio, nos inclinamos a ver en ella más bien síntomas de debilidad. La excesiva presencia del capital reduce la complejidad de la sociedad e impide la adecuada comprensión de la forma-Estado. Lo dominante es la relación perfectamente homogénea, sin residuos, entre economía y política. Extendiéndose hasta comprender toda la vida social preestatal, la economía se convierte en la «estructura» fundamental del sistema. La antítesis sociedad-Estado puede entonces ponerse en relación con otra antítesis clásica, aquella entre estructura y superestructura. Si es cierto que el momento superestructural no se agota en el Estado, no lo es menos que la sociedad tiende a coincidir con la estructura económica ${ }^{55}$.

Por esta vía el Estado se presentará cada vez más como elemento subordinado, lo cual explica por qué Marx en sus escritos de madurez se ha ocupado sobre todo de la crítica de la economía política, descuidando en gran medida las cuestiones inherentes al Estado. Das Kapital se muestra entonces como la interpretación de un movimiento histórico determinado y determinante: el advenimiento de la moderna sociedad capitalista. La teoría de Marx se tornará la hermenéutica de esta sociedad, en la que el Estado resulta ser sólo un medio. Funciona inmediatamente un mecanismo de síntesis que, si bien tal vez servía para explicar la situación histórica que emerge con el desarrollo de la técnica y de la industria, se revela en cambio insuficiente para explicar las nuevas condiciones. Así, su teoría, paradójicamente, más que ofrecer la anticipación de nuevos horizontes, permanece en gran medida anclada en su época. Y precisamente ahí donde surge su límite se pone de manifiesto una vez más la incidencia de Hegel.

${ }^{55}$ Véase el célebre pasaje del Vorwort a Zur Kritik der politischen Ökonomie (1859), en el que Marx dice que «la anatomía de la sociedad civil hay que buscarla en la economía política» y a continuación presente la tesis de la relación estructura-superestructura en una de sus más célebres formulaciones. [Hay tr. cast.: Contribución a la Crítica de la Economía Política, México, Editora Nacional, 1966. pág. 7]. 


\section{SIGNOS Y ABREVIATURAS UTILIZADOS}

A Observación (Anmerkung) al párrafo citado.

HE Enzyklopädie der philosophischen Wisssenschaften im Grundrisse, Heildebert, 1817, que respecto a la sección dedicada al espíritu objetivo, cito por la edición a cargo de K.-H. Ilting, reproducida en G. W. F. Hegel, Vorlesungen über Rechtsphilosophie, Stuttgart-Bard Cannstatt, Fromma-Holsboog, 1973-1974. [Hay tr. cast. de E. Ovejero: Enciclopedia de las ciencias filosóficas, México, Porrúa, 1971].

Rph Grundlinien der Philosophie des Rechts, Berlin, 1821, que cito de la edición a cargo de K.-H. Ilting, reproducida en G. W. F. Hegel. Vorlesungen über Rechtsphilosophie, vol. II. Los números que siguen al párrafo indican las páginas y las líneas. [Se ha utilizado la tr. cast. de Juan Luis Vermal: Principios de la Filosofía del derecho, Barcelona, Edhasa, 1988, que incluye las «observaciones» del autor y los «agregados» que hiciera el primer editor de la obra de Hegel, E. Gans, sobre la base de los apuntes de los alumnos].

Rph I Vorlesungen über Rechtsphilosophie 1817/18, que cito de la edición a cargo de K.-H. Ilting, publicada en G. W. F. Hegel, Die Philosophie des Rechts. Die Mitschriften Wannenmann (Heildelberg 1817/18) und Homeyer (Berlin 1818/19), Stuttgart, Klett-Cotta, 1983.

Rph II Vorlesungen über Rechtsphilosophie 1817/18, que cito de la edición a cargo de K.-H. Ilting, publicada en G. W. F. Hegel, Die Philosophie des Rechts. (Cfr. Rph I). [Hay tr. cast.: Lecciones sobre filosofía del derecho. Berlín 1818-19, Morón, Ed. Universitaria de Morón, 1983].

Rph III Vorlesungen über Rechtsphilosophie 1819/20, que cito de la edición a cargo de D. Henrich: Philosophie des Rechts, Frankfurt a. M., Suhrkamp, 1983. Los números de $R p h$ III se refieren a las páginas y a las líneas.

Rph IV Vorlesungen über Rechtsphilosophie 1821/22 (que cito de la transcripción aún inédita de H. Hoppe).

Rph V Vorlesungen über Rechtsphilosophie 1821/22, que cito de la edición a cargo de K.-H. Ilting, reproducida en G. W. F. Hegel, Vorlesungen über Rechtsphilosophie, vol. III.

Rph VII/Rph VII Vorlesungen über Rechtsphilosophie 1824/25 y 1831, que cito de la edición a cargo de K.-H. Ilting, reproducida en G. W. F. Hegel, Vorlesungen über Rechtsphilosophie, vol. IV.

$R p h, R p h$ I, etc. Con tales siglas se indican en el texto también las respectivas introducciones y notas de Ilting, y de Henrich, sin que ello genere nunca confusión. 
DOXA-14 (1993)

$\triangle$ 